
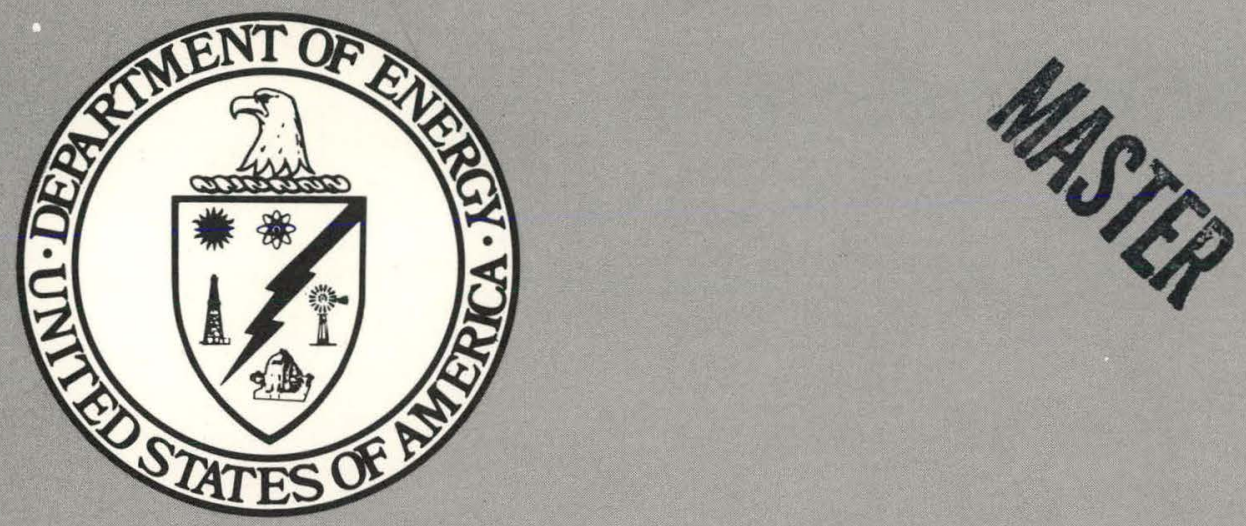

CEND-377(Vol.1)

CONCEPTUAL DESIGN OF A LARGE SPECTRAL

SHIFT CONTROLLED REACTOR

By
R. A. Matzie
G. P. Menzel

August 1979

Work Performed Under Contract No. EN-77-C-01-5070

C-E Power Systems

Combustion Engineering, Inc.

Windsor, Connecticut 


\section{DISCLAIMER}

This report was prepared as an account of work sponsored by an agency of the United States Government. Neither the United States Government nor any agency Thereof, nor any of their employees, makes any warranty, express or implied, or assumes any legal liability or responsibility for the accuracy, completeness, or usefulness of any information, apparatus, product, or process disclosed, or represents that its use would not infringe privately owned rights. Reference herein to any specific commercial product, process, or service by trade name, trademark, manufacturer, or otherwise does not necessarily constitute or imply its endorsement, recommendation, or favoring by the United States Government or any agency thereof. The views and opinions of authors expressed herein do not necessarily state or reflect those of the United States Government or any agency thereof. 


\section{DISCLAIMER}

Portions of this document may be illegible in electronic image products. Images are produced from the best available original document. 


\section{DISCLAIMER}

"This book was prepared as an account of work sponsored by an agency of the United States Government. Neither the United States Government nor any agency thereof, nor any of their employees, makes any warranty, express or implied, or assumes any legal liability or responsibility for the accuracy, completeness, or usefulness of any information, apparatus, product, or process disclosed, or represents that its use would not infringe privately owned rights. Reference herein to any specific commercial product, process, or service by trade name, trademark, manufacturer, or otherwise, does not necessarily constitute or imply its endorsement, recommendation, or favoring by the United States Government or any agency thereof. The views and opinions of authors expressed herein do not necessarily state or reflect those of the United States Government or any agency thereof."

This report has been reproduced directly from the best available copy.

Available from the National Technical Information Service, U. S. Department of Commerce, Springfield, Virginia 22161.

Price: Paper Copy $\$ 9.00$

Microfiche $\$ 3.50$ 
CEND-377(Vol.1)

Distribution Category UC-78

\title{
CONCEPTUAL DESIGN of a LARGE SPECTRAL SHIFT CONTROLLED REACTOR
}

\author{
VOLUME I
}

\author{
prepared for the \\ UNITED STATES DEPARTMENT OF EMERGY \\ under \\ CONTRACT No. EN-77-C-01-5070
}

August 1979

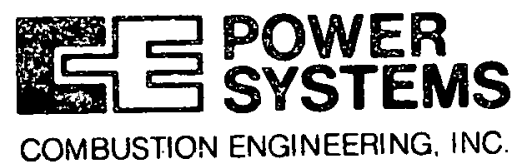


CONCEPTUAL DESIGN OF A LARGE

SPECTRAL SHIFT CONTROLLED REACTOR

By

R. A. MATZIE and G. P. MENZEL

August 1979

The material contained in this report represents the cooperative effort of many individuals. In particular, the contribution by the Stone \& Webster Engineering Corporation in establishing the PWR plant modifications to realize spectral shift control, and the contribution by the C-E Lummus Company in developing the $\mathrm{D}_{2} \mathrm{O}$ upgrader design are gladly acknowledged. In addition, the advice and colnsel of Drs. R. L. Hellens and N. L. Shapiro of Combustion Engineering, Inc. are deeply appreciated. The contributions of the following individuals whose efforts made this report possible are hereby acknowledged.
R. W. Beekmann
R. F. Brown
A. T. Chen
H. R. Freeburn
M. C. Jacob
H. F. Jones
M. A. Krammen
Y. Liu
E. S. Markowski
J. H. Mason
J. C. Muller
K. Paduch
S. R. Pati
J. R. Rec
T. A. Schultz
F. M. Sider
G. U. Singco
J. A. Zelez

G. D. Gowdy

C-E Lummus Company

F. K. Giaccio

R. C. Johnson

R. K. Barchas 


\section{ABSTRACT}

Within the framework of the Nonproliferation Alternative Systems Assessment Program (NASAP), the U.S. Department of Energy (DOE) has sponsored the development of a conceptual design of a large Spectral Shift Controlled Reactor (SSCR). This report describes the results of the development program and assesses the performance of the conceptual SSCR on the basis of fuel resource utilization and total power costs. The point of departure of the design study was a 1270 MW(e) PWR using Combustion Engineering's System $80^{\mathrm{TM}}$ reactor and Stone \&. Webster's Reference Plant Design. The initial phase of the study consisted of establishing an optimal core design for both the once-through uranium cycle and the denatured U-235/ thorium cycle with uranium recycle. The performance of the SSCR was then also assessed for the denatured U-233/thorium cycle with uranium recycle and for the plutonium/thorium cycle with plutonium recycle. After the optimal core design was established, the design of the NSSS and balance of plant was developed.

Because of the elimination of neutron losses in control poisons and the associated improvement in fuel utilization efficiency, the fuel resource requirements of the SSCR are $11 \%$ less than those of the LWR for the $\mathrm{UO}_{2}$ once-through and the denatured $U-235 /$ thorium cycles. The net fissile requirement of the denatured $U-233 /$ thorium cycle is $27 \%$ lower than that of the similarly fueled PWR when both U-233 and fissile plutonium are considered. The improvement in fissile consumption is considerably less for the plutonium/thorium SSCR; a reduction of only $8 \%$ in the net fissile requirement is obtained for this cycle. The resulting savings in fuel 
cost are balanced by additional plant capital costs ( $\$ 26$ million) and heavy water inventory costs ( $\$ 54$ million), so that the power costs of the SSCR are comparable to those of the conventional LWR for the $\mathrm{UO}_{2}$ once-through cycle only when the price of uranium exceeds about $\$ 100 / 1 \mathrm{~b} \mathrm{U}_{3} \mathrm{O}_{8}$. For the denatured U-235/thorium SSCR, the power costs become competitive with those of the $\mathrm{UO}_{2}$ once-through cycle at even higher uranium prices.

Since the SSCR is basically a PWR with an alternate depletion-reactivity control system, its response to accident conditions is, in general, similar to that of the PWR. It does not appear, therefore, that the SSCR is confronted with any significant licensing issues which arise from spectral shift operation. Given the necessary economic incentive, the prospect of early deployment of the SSCR should be significantly better than that of other alternative systems because it is based on proven LWR technology and because the risk associated with deployment is limited to the cost of additional equipment, estimated to be only about $4 \%$ of the total cost of the plant. It appears unlikely, however, that the SSCR will be adopted by the electrical utility industry because of its poor economics in the near-term and general lack of operating data/licensing experience. 
Abstract

2. Introduction

2.1 Study Objectives

2.2 The Spectral Shift Controlled Reactor Concept

2.3 Role of the SSCR in NASAP

2.4 Previous SSCR Development

3. Summary

3.1 Summary Description of SSCR

3.1.1 Design Approach

3.1.2 Overall Plant Layout 3-3

3.1.3 Core Design 3-5

3.1.4 Fuel Design 3-6

3.1.5 Primary Coolant System 3-9

3.1.6 Adjustment of Coolant Concentration 3-12

3.1.7 $\mathrm{D}_{2} \mathrm{O}$ Upgrader $\quad 3-20$

3.1.8 Refueling $3-26$

3.1.9 $\mathrm{D}_{2} \mathrm{O}$ Inventory

3.1.10 $\mathrm{D}_{2} \mathrm{O}$ Leakage $3-29$

3.1.11 Load Change Capability $\quad \because \quad 3-32$

3.2 Resource Utilization and Economic Analysis 3-34

3.2.1 Resource Requirements 3-34

3.2.2 Total Power Generation Costs 3-42

3. 3 Fuel Management in the Spectral Shift Controlled Reactor 3-49

3.3.1 Difference Between Fuel Management in the SSCR and in the PWR

3.3.2 UO ${ }_{2}$ Once-Through SSCR Core $\quad 3-52$

3.3.3. $\mathrm{ThO}_{2}$ SSCR Cores 3-53

3.4 Safety and Licensing 3-57

3.4.1 Safety-Related Plant Parameters 3-57

3.4.2 Accident Analysis 3-58 
3.4.4 Tritium Release During Normal Operation 3-61

3.4.5 Licensability 3-63

3.5 Research and Development 3-64

3.6 Commercial Introduction of the SSCR 3-67

3.7 Conclusions and Recommendations 3-71

3.7.1 Conclusions 3-71

3.7.2 Recommendations $\quad 3-75$

VOLUME II

4. Optimization of the Spectral Shift Controlled Reactor Plant Design

4. 1 Purpose of Optimization 4-1

4.2 Optimization Procedure 4-4

4.3 Core Parameters 4-7

4.4 Impact of Core Optimization on Overall Reactor Plant 4-10

4.5 Optimization of the $\mathrm{UO}_{2}$. Once-Through Fuel Cycle 4-12

4.5.1 Effect of Reducing the Fuel Stack Density 4-13

4.5.2 Effect of Increasing the Fuel Discharge
Exposure

4.5.3 Effect of Varying the Number of Fuel Batches 4-18

4.5.4 Effect of Modifying the Fuel Rod Pitch 4-20

4.5.5 Effect of Modifying the Fuel Rod Diameter 4-23

4.5.6 Effect of Combining Increased Fuel Discharge
Exposure with More In-Core Batches

4.6 Optimization of the Denatured U-235/Thorium. Fuel Cycle 4-28

4.6.1 Effect of Reducing the Fuel. Stack Density 4-30

4.6.2 Effect of Increasing the Fuel Discharge Exposure 4-32

4.6.3 Effect of Varying the Number of Fuel Batches 4-34

4.6.4 Effect of Modifying the Fuel Rod Pitch 4-36

4.6.5 Effect of Modifying the Fuel Rod Diameter: 4-38

4.6.6 Effect of Employing Higher Heavy Water $\quad \cdots$
Concentrations

4.7. Other Fuel Cycles $4-41$

4.8 Selection of the SSCR Reference Core Design 4-43 
5. SSCR Reference Design

5.1 Description of SSCR Reference Design 5-1

5.1.1 Design Approach 5-1

5.1.2. Description of Plant Layout 5-4

5.1.3 Core Design . 5-37

5.1 .4 . Fuel Design 5-39

5.1.5 Reactor Coolant System 5-66

5.1.6 Plant Systems for the Management of Coolant Concentrations

5-75

5.1.7 Modifications to Balance-of-Plant Systems $\quad 5-91$

5.1.8 $\mathrm{D}_{2} \mathrm{O}$ Upgrader Design 5-101

5.1.9 $\mathrm{D}_{2} \mathrm{O}$ Leakage and Losses 5-126

$5.1 .10 \quad \mathrm{D}_{2} 0$ Inventory 5-142

5.1.11 Refueling 5-151

5.1.12 Coolant Management Operations $\quad$ 5-157

5.1.13 Load Change Capability 5-216

5.1.14 Heat Balance 5-231

5.2 Resource Utilization and Economics of SSCR Reference Design

$5-236$

5.2.1 General 5-236

5.2.2 Description of Fuel Cycles 5-236

5.2.3 Resource Utilization 5-243

5.2.4 Economic Evaluation 5-267

5.2.5 Comparison of the SSCR and PWR Performance 5-292

5.3 Fuel Management in the SSCR 5-301

5.3.1. Introduction : 5-301

5.3.2 $\mathrm{UO}_{2}$ Once-Through Fuel Cycles 5-303

5.3.3. Thorium Fuet Cycles 5-324

5.3.4 Comparison of SSCR and PWR Fuel Management 5-357

5.4 Safety Assessment 5-361

5.4.1 Determination of Core Physics Parameters 5-361

5.4.2 Loss-of-Coolant Accident 5-381

5.4.3 Accident Analysis Excluding Loss-of-Coolant
Accident 
5.4.4 Tritium Exposure During Normal Operation

5.4.5 Neutron Fluence on Reactor Vessel

5.4.6 Long-Term Cooling

5.5 Environmental Impact of SSCR

5.5.1 Effect of Tritium Release on Allowable Site Boundary Dose

5.5.2 $\mathrm{D}_{2} \mathrm{O}$ Upgrader Facility

6. Commercial Introduction of the SSCR

6. 1 Possible Scenarios for Introduction of the SSCR

6.1.1 General

6.1.2 Routes for Introducing the SSCR

$6-2$

6.1.3 Potential Introduction Dates for the SSCR

$6-5$

6.2 Technical Problem Areas

\subsubsection{General}

$6-10$

6.2.2 SSCR-Features Requiring Special Attention

$6-74$

6.3 Licensability

6-20

6.4 Commercial Viability of the SSCR

$6-23$

6.4.1 Utility Perception of the Need for an Advanced Converter

6-23

6.4.2 Potential Benefits of the SSCR-Are They Sufficient?

6.4.3 The Costs of Spectral Shift Control Who Will Pay?

6-25

6.4.4 Prospect of Success

6.4.5 Summary of Commercial Viability

6.5 Required Research and Development

6.5.1 Refueling Coolant Exchange

6-35

6.5.2 $\mathrm{D}_{2} \mathrm{O}$ Concentration Measurements

6-36

6.5.3 Critical Heat Flux Data

6.5.4 Physics Verification

6-38

6.5.5 Tritium Releases

6-39

6.5.6 Tritium Separation

6-39

6.5.7 Cost of $\mathrm{D}_{2} \mathrm{O}$

$6-40$

6.5.8 $\mathrm{D}_{2} \mathrm{O}$ Upgrader Development 
6.5.9 Development of a Preliminary Safety Analysis Report (SAR) for the SSCR

6. 6 Backfitting Potential

6.6.1 General

6.6.2 Backfitting Existing PWR for Spectral Shift Operation

6.6.3 Backfitting PWR for Spectral Shift Control Operation During Construction of Plant

7. Appendices

7. 1 Calculation of Tritium Concentration in Containment Building

7.2 Calculation of Dilution Steam Requirements 7-5

7.3 Calculation of Evaporation from Refueling Cavity 7-9

7.4 Specifications for $\mathrm{D}_{2} \mathrm{O}$ Upgrader Plant 7-12

7.4.1 Function, Processing Scheme, and Operating Conditions

7.4.2 Charge Stocks and their Specifications 7-12

7.4.3 Charge Rate 7-13

7.4.4 Products and their Specifications 7-13

7.4.5 Yields of Products 7-14

7.4.6 Battery Limit Conditions 7-15

7.4.7 Utilities and Their Specifications 7-16

7.4.8 Estimated Utilities Consumptions 7-18

$\begin{array}{lll}7.5 \mathrm{D}_{2} \mathrm{O} \text { Upgrader Equipment List } & \text { 7-19 }\end{array}$

$\begin{array}{lll}7.6 & \mathrm{D}_{2} \mathrm{O} \text { Upgrader Heat Balance } & 7-21\end{array}$

7.6.1 Steam and Condensate System 7-21

7.6.2 Cooling Water System 7-23

$\begin{array}{ll}7.7 & \text { Physics Analysis Methods 7-25 }\end{array}$

7.7.1 General 7-25

7.7.2 CEPAK Lattice Cell Code 7-25

7.7.3 Development of Spatial Diffusion Mode 1 7-27

7.7.4 Procedure for Analyzing SSCR Fuel Cycles 7-29

7.8 Prant Cost Estimates. $\quad \ldots \ldots 7-33$

7.9 Reactor Fuel Cycle Charge and Discharge Inventory Data 


\section{VOLUME I}

\section{FIGURES}

Figure

Title

Page

3. 1. 2-1

Plot Plan - SSCR

3-4

$3.1 .3-1$

Reactor Core Cross Section

$3-7$

3. 1. 3-2

Reactor Vertical Arrangement

3-8

3. 1. 4-1

Fission Gas Accommodation

3-10

3. 1.6-1

PWR Plant Systems

$3-14$

$3.1 .6-2$

SSCR Plant Systems

$3-15$

3. 1. 7-1

SSCR Heavy Water Upgrader, Distillation Section

$3-21$

3. 1. 7-2

SSCR Heavy Water Upgrader, Product Recovery Section

$3.1 .7-3$

SSCR Heavy Water Upgrader, Plot Plan

$3-23$

3. 1. 7-4

SSCR Heavy Water Upgrader

$3-24$

$3.1 .8-1$

SSCR-Study Refueling-Coolant Exchange

$3-27$ 
VOLUME I

TABLES

$\underline{\text { Table }}$

$1-1$

$1-2$

3. 1. 1-1

3.1.9-1

3. $2.1-1$

3. $2.7-2$

3. 2. 2-1

3. 2. 2-2
Title

Potential Improvements in Uranium Utilization

Breakeven U-233 Prices for a SSCR

General Reactor Performance Parameters

SSCR Study $\mathrm{D}_{2} \mathrm{O}$ Inventory

Estimated Fuel Resource Requirements for PWR and SSCR

Estimated Special Fuel Requirements for PWR and SSCR

Economic and Resource Parameters

Total Power Costs
Page

$1-4$

$1-7$

3-2

3-30

3-39

3-41

3-45

3-46

$x i j$ 


\section{SECTION 1 - EXECUTIVE SUMMARY}

Within the framework of the Nonproliferation Alternative Systems Assessment Program (NASAP), and under the sponsorship of the U.S. Department of Energy, Combustiun Englneering, inc. has developed the conceptual design of a large Spectral Shift Controlled Reactor (SSCR). The SSCR is a PWR in which the soluble boron normally employed for reactivity-depletion control is replaced by $\mathrm{D}_{2} \mathrm{O}$ addition to the primary coolant. This causes more absorption of neutrons in fertile material and, thus, results in the production of additional fissile material.

The basic approach in developing the conceptual design of the SSCR was to start with Combustion Engineering's System $80^{\text {TM }} 3800$ MW(th) PWR and Stone \& Webster's 1300 MW(e) Reference Nuclear Power Plant and modify them for spectral shift control while retaining the capability for operation with conventional poison control. Optimization studies of the SSCR showed that the System $80^{\text {TM }}$ PWR core configuration is a good choice for both the oncethrough fuel cycle and fuel cycles employing recycle of bred fuels. Thus, the reactor core, reactor vessel and internals, as well as the rest of the main coolant loops are essentially identical to those of the System $80^{\mathrm{TM}}$ reactor. Spectral shift control operation, however, does require modifications of the auxiliary systems of the primary coolant loops and of various plant support systems because (a) the $\mathrm{D}_{2} \mathrm{O}$ concentration needs to be adjusted during a core operating cycle (from about 60 wt\% at the beginning to 2 wt\% at the end), and (b) coolant losses need to be minimized due to the high cost of $\mathrm{D}_{2} 0$ (about $\$ 100 / 1 \mathrm{~b}$ ) and the increased tritium radiological hazard associated with $\mathrm{D}_{2} \mathrm{O}$ in the coolant (tritium concentrations in the coolant are 
several hundred times higher than in the PWR).

The most conspicuous single modification was the addition of a 1725 gal/day $\mathrm{D}_{2} \mathrm{O}$ upgrader facility to reconcentrate diluted $\mathrm{D}_{2} \mathrm{O}$. The facility consists of three vacuum distillation columns which are similar to those in service at Canadian Heavy Water Reactor power plants. Additional major equipment modifications are required for the Chemical and Volume Control System and its subsystems; they include increasing the boron evaporator capacity (from $25 \mathrm{gpm}$ to $135 \mathrm{gpm}$ ) to the capacity of the charging pumps as well as augmenting (from about 1.2 to 1.65 million gallons) the tankage capacity for storing various $\mathrm{D}_{2} \mathrm{O}$ concentrations. The larger boron evaporators and the increased tank capacity necessitated compartment rearrangements in the Annulus Building and the enlargement of the Solid Waste and Decontamination Building.

In order to minimize $\mathrm{D}_{2} \mathrm{O}$ leakage from $\mathrm{D}_{2} \mathrm{O}$-containing systems, canned rotor centrifugal pumps and zero-leak valve designs are employed. Many of these components can be of conventional design since the auxiliary systems generally operate at pressures an order of magnitude lower than that of the primary system. A similar design approach was successfully applied at the: Argentinian 340 MW(e) Atucha Heavy Water Reactor, which is a pressure vessel heavy water reactor with PWR-type auxiliary systems. Operating experience with this plant shows that annual irrecoverable $\mathrm{D}_{2} \mathrm{O}$ losses can be kept below $0.5 \%$ of the $\mathrm{D}_{2} \mathrm{O}$ inventory.

The high $\mathrm{D}_{2} \mathrm{O}$ cost and the tritium inventory generated during operation also affect refueling. The basic PWR refueling procedure has been retained but 
has been modified to reduce loss of $D_{2} 0$ by dilution with light water from the Refueling Water Storage Tank, and to limit the tritium concentration in the containment building due to evaporation from the refueling pool.

Before removing the reactor vessel head, the primary system is drained to the level of the main coolant pipe centerlines in order to minimize the $\mathrm{D}_{2}$ 0-containing water volume remaining in the reactor vessel. This residual coolant volume is then flushed out and replaced with borated light water from the Refueling Water Storage Tank. Thereafter, refueling proceeds as in the PWR.

Due to its improved neutron economy, the fuel utilization of the SSCR is better than for a conventional PWR. Four fuel cycles were analyzed as part of the evaluation of the spectral shift control concept:

- the $\mathrm{UO}_{2}$ once-through cycle with permanent disposal of spent fuel,

- the denatured $\mathrm{U}-235 / \mathrm{ThO}_{2}$ cycle with recycle of recovered uranium and sale or storage of bred plutonium,

- the denatured $\mathrm{U}-233 / \mathrm{ThO}_{2}$ cycle with recycle of recovered uranium and sale or storage of bred plutonium, and

- the plutonium $/ \mathrm{ThO}_{2}$ cycle with recycle of plutonium and sale of U-233.

The analysis showed that the savings in $\mathrm{U}_{3} \mathrm{O}_{8}$ requirements due to spectral shift control operation relative to poison control operation are about $10 \%$ for the $\mathrm{UO}_{2}$ once-through fuel cycle and between $11 \%$ and $14 \%$ for the denatured $\mathrm{U}-235 / \mathrm{ThO}_{2}$ cycle, depending on whether plutonium is stored or utilized. Additional analyses of the $\mathrm{UO}_{2}$ once-through cycle (See Táble 1-1) showed that by supplanting the conventional fuel management scheme (three fuel 
Modification

Unmodified ${ }^{(1)}$

Decreased Fuel Density ${ }^{(2)}$

Increased Burnup

Increased Number

of Fuel Batches (3)

Increased Fue 1

Rod Pitch (2)

Decreased Fuel

Rod Diameter (2)

Increased Burnup

and Number of Batches

$$
\begin{aligned}
& \mathrm{UO}_{2} \text { Once-Through Cycle } \\
& \text { PWR } \quad \text { SSCR }
\end{aligned}
$$

REFERENCE $\quad 10 \%$

$1 \% \quad 16 \%$

$5 \%$

$17 \%$

$9 \% \quad 17 \%$

$2 \% \quad 15 \%$

$2 \% \quad 17 \%$

$11 \% \quad 21 \%$

NOTES: (1) Conventional three batch fuel management with annual refueling and $30,400 \mathrm{MWd} / \mathrm{t}$ discharge burnup.

(2) Improvements for PWR limited by foderator Temperature Coefficient (MTC).

(3) Values given for five batches: and: constant 30,400 $\mathrm{m} \% \mathrm{~d} / \mathrm{t}$ discharge hurnup. 
batches, $30,400 \mathrm{MWd} / \mathrm{t}$ average burnup). with a scheme employing five fuel batches and 50,650 MWd/t average burnup, further savings in $\mathrm{U}_{3} \mathrm{O}_{8}$ of about $11 \%$ can be realized for the SSCR as well as for the conventional PWR. When operating on the denatured $\mathrm{U}-233 / \mathrm{ThO}_{2}$ cycle, the SSCR consumes $17 \%$ less $\mathrm{U}-233$ over the plant life than a PWR, while at the same time producing about 16\% more fissile plutonium. With respect to the plutonium/ $\mathrm{ThO}_{2}$ cycle, a SSCR produces about $12 \%$ more U-233 per quantity of fissile plutonium consumed than a PWR.

The better fuel utilization of the SSCR is reflected in lower fuel cycle costs. However, the capital costs of the SSCR are higher, because of the $\mathrm{D}_{2} \mathrm{O}$ inventory (about $\$ 54 \mathrm{million}$ ), plant equipment modifications and additions (about $\$ 16$ million) and the addition of the $\mathrm{D}_{2} 0$ upgrader (about $\$ 10$ million). Also, the operating and maintenance costs of a SSCR are estimated to be $0.1 \mathrm{mills} / \mathrm{kWh}$ higher than for a PWR. For the $\mathrm{UO}_{2}$ fuel cycle, the lower fuel cycle costs compensate, to a large extent, for higher capital costs so that the SSCR has power costs about $0.5 \mathrm{mills} / \mathrm{kWh}$ higher than a PWR at present uranium prices (\$40/1b) and competitive power costs at $\$ 100 / 1 \mathrm{~b} \mathrm{U}_{3} \mathrm{O}_{8}$. With denatured $\mathrm{U}-235 / \mathrm{ThO}_{2}$ fuel, the SSCR power costs are higher than those of the PWR, even at $\$ 100 / 1 \mathrm{~b} \mathrm{U}_{3} \mathrm{O}_{8}$. Moreover, the denatured $\mathrm{U}-235 / \mathrm{ThO}_{2}$ fueled $\mathrm{SSCR}$ is not competitive with the $\mathrm{UO}_{2}$ fueled SSCR for any realistic uranium price (far in excess of $\$ 100 / 1 b$ ).

An economic comparison of the U-235 fueled SSCR cycles with the denatured U-233/ThO ${ }_{2}$ or the plutonium/ThO 2 SSCR cycles is difficult in the absence of results from a systems analysis to assign a proper value to $\mathrm{U}-233$ and 
fissile plutonium. However, with representative plutonium values of $\$ 17 / \mathrm{gm}$ fissile (estimated near-term value) and $\$ 46 / \mathrm{gm}$ fissile (estimated long-term value), U-233 prices can be determined such that the power costs of the denatured $\mathrm{U}-233 / \mathrm{ThO}_{2}$ cycle or the plutonium/ $/ \mathrm{ThO}_{2}$ cycle break even with the power cost of the $\mathrm{UO}_{2}$ once-through SSCR cycle employing five fuel batches and 50,650 MWd/t burnup. Table 1-2 gives these U-233 breakeven prices. In the near term, U-233 would have to be purchased for less than $\$ 11 / \mathrm{gm}$ for the denatured $\mathrm{U}-233 / \mathrm{ThO}_{2} \mathrm{SSCR}$ and would have to be sold for over $\$ 32 / \mathrm{gm}$ for the plutonium $/ \mathrm{ThO}_{2}$ SSCR to obtain power costs equal to that of the $\mathrm{UO}_{2}$ oncethrough, five-batch SSCR. Because of this disparity between the breakeven buy and sell prices of $U-233$ in the near.term, a reactor economy in which only SSCRs produce and consume U-233 would not be competitive with the $\mathrm{UO}_{2}$ once-through cycle. In the long term, the breakeven U-233 values for the two fuel cycles are compatible, namely below $\$ 68 / \mathrm{gm}$ for the denatured $\mathrm{U}-233 / \mathrm{ThO}_{2}$ cycle and above $\$ 57 / \mathrm{gm}$ for the plutonium/ThO ${ }_{2}$ cycle. With U-233 prices in this range, power costs comparable to those of the $\mathrm{UO}_{2}$ oncethrough, five-batch SSCR can be obtained. Since the $\mathrm{VO}_{2}$-fueled SSCR is competitive with the $\mathrm{UO}_{2}$-fueled PWR in the long term, the SSCR operating on the two thorium cycles can be competitive with the PWR as long as the price of U-233 falls within the above breakeven range.

The assessment of the response of the SSCR to accident conditions has not uncovered any significant safety or licensing issues. Some safety-related parameters of the SSCR (e.g., the more negative moderator temperature coefficient at beginning of cycle and the reactivity addition via accidental dilution of coolant with light water) cause the response of the SSCR to 
TABLE $1-2$

BREAKEVEN U-233 PRICES FOR THE SSCR ${ }^{\mathrm{a}}$

Fuel Cycle

Near-term

Long-term

Cost Assumptions

Cost Assumptions

Denatured U-233/Thorium ${ }^{b}$

$\$ 11 / \mathrm{gm}$

$\$ 68 / \mathrm{gm}$

Plutonium/Thoriumb

$\$ 32 / \mathrm{gm}$

$\$ 57 / g m$

NOTE: a. U-233 price which gives fuel cycle costs equal to that of the $\mathrm{UO}_{2}$ once-through, five-batch SSCR.

b. Plutonium fissile values of $\$ 17.42 / \mathrm{gm}$ and $\$ 46.24 / \mathrm{gm}$ used for the near-term and long-term cost assumptions, respectively. 
certain accidents to be less desirable than for a PWR. However, the safety evaluation of the SSCR did not indicate that safety criteria are exceeded. Tritium production in the SSCR is considerably greater than in the PWR, leading to tritium concentrations in the coolant which are several hundred times higher. Apart from contributing to the necessity of modifying the refueling procedure and requiring the adoption of stricter plant maintenance and repair procedures, the higher tritium concentration could also affect the activity release to the environment during normal plant operations. The activity level is essentially determined by the amount of leakage from the primary to secondary system in the steam generators. Assuming conservatively high tritium concentrations, it appears that a leakage up to about $30 \mathrm{lb}$. liquid per day does not appear to result in significant plant siting restrictions for the SSCR relative to a PWR. For comparison, operating experience shows that the majority of PWR steam generators have no detectable leakage. In summary, it is expected that a SSCR can be licensed after a detailed design has been developed and the safety analysis has been submitted for review.

The proof of principle of spectral shift operation was demonstrated by the Vulcain experiment in the BR-3 nuclear plant at Mol, Belgium. The BR-3 plant, after two years of operation as a conventional 11 MW(e) PWR, was modified for spectral shift control and successfully operated with this mode of control between 1966 and 1968. Subsequently, the BR-3 reactor was returned to conventional PWR operation. The present SSCR study confirms the conclusions of the earlier work as to the close resemblance of the SSCR to a conventional. PWR. The specific modifications for SSCR operation 
utilize components and design concepts which are in use either in the light water or heavy water reactor field. Although no technological breakthrough or major developments of key components are required, the deployment of the spectral shift option will require some engineering development work totaling at least several million dollars, primarily for experimental verification of proposed plant operations and analysis methods.

The prospects for deployment of the SSCR are good from the technological point of view. Due to the close similarity of the SSCR to the PWR, the manufacturing capacity and techniques are established and the accomplishment of the required engineering development appears to pose no significant problems. The introduction of the SSCR would not necessarily require the construction of a prototype plant. Instead, the capability for spectral shift control can be included in the design of a new PWR or even backfitting an existing PWR appears feasible. Since the SSCR can always be operated in the conventional poison control mode, there is no risk to the generating capacity of a power station if a SSCR is deployed. The financial risk is limited to the cost of the additional equipment to realize spectral shift control, which is estimated to be only about $4 \%$ of the total plant cost.

With respect to power costs, the outlook is more uncertain. A power cost advantage of the SSCR over the PWR is not expected before uranium prices reach about $\$ 100 / 1 \mathrm{~b} \mathrm{U}_{3} \mathrm{O}_{8}$. However, from a commercialization standpoint, the SSCR should probably be viewed as a major advancement in the evolution of the PWR. A number of modifications/operating strategies beyond the use of high 
burnup and an increased number of fuel batches, which show considerably less potential for improved fuel utilization than spectral shift control, are currently being investigated for the PWR. It appears that a larger benefit can be obtained in less time and with less development effort by adopting the spectral shift concept than by combining a number of marginal improvements for the poison controlled PWR.

Any discussion of the commercialization aspects of a reactor type would be incomplete without consideration of the licensing process. Past experience has shown that it is difficult to judge the licensability of a new reactor concept prior to developing a detailed design. In particular, for a reactor type which is not presently deployed in the U.S., even the appropriate acceptance criteria and design standards would need to be developed. For the SSCR, on the other hand, most of the criteria and standards do exist in the form of PWR criteria and standards and would be applicable to the SSCR because of its close similarity to the PWR.

What remains the overriding consideration for the successful development of the SSCR is whether/when it will be able to compete economically with the conventional LWR. Unless some intangible or external factor influences the decision process, the SSCR will not be adopted in the near-term because of its higher power generation costs. In the long-term, when the price of uranium becomes high enough, the spectral shift control concept will become attractive. However, if the necessary development and demonstrations have not been completed, the concept will not be available for deployment at that time. 
INTRODUCTION

In his energy statement of Apri1 7, 1977, President Carter annunciated a nuclear policy emphasizing nonproliferation of nuclear weapons. Implementation of the policy defers both the commercial use of plutonium and the development of the plutonium fast breeder. By inference, it places increased emphasis as well on fuel-efficient converter reactors when the presently anticipated limits of uranium ore resources are considered. Exclusive dependence on the continued use of once-through uranium fueling of light-water reactors implies an electrical energy production potential from nuclear sources which is smaller than if recycle were employed and maybe smaller than prudent planning can accept. This will be particularly true if future technology development allows the transfer of an appreciable fraction of demand presently met by imported energy to the electrical supply sector. In this context, more efficient use of nuclear fuel, consistent with the new policy concerning nonproliferation, is of immediate interest and is the central thrust of the present round of studies under the Nonproliferation Alternate Systems Assessment Program (NASAP) undertaken by the U.S. Department of Energy.

The study of the Spectral Shift Controlled Reactor (SSCR) presented in this report is primarily intended to delineate the extent to which this particular reactor concept, coupled with various fuel cycles, could contribute to the 
multiple goals of fuel efficiency, nonproliferation and economic power generation. As in other NASAP projects, the approach has been to evaluate resource utilization, commercialization potential, licensing, safety and environmental issues as they affect the performance of a large $1260 \operatorname{MN}(e)$ generating piant.

of the various reactor systems which show higher fueling efficiency (short tons $\mathrm{U}_{3} \mathrm{O}_{8}$ per GWe) than the conventional LWR, the spectral shift controlled reactor (SSCR) makes the greatest use of the LWR technology and components al ready highly developed in the U.S. and most of the rest of the world. In this concept, the excess neutrons generated during operation of the reactor are directed preferentially to capture in fertile material, rather than control poison, by alteration of the heavy-water-to-normal-light-water ratio in the coolant. Thus, more fissile material is produced and burned in situ during operation than in the conventional LWR.

The basic idea of the SSCR is not new but was developed during the early 1960 s with the expectation that a demonstration plant would be built in the U.S. At the time, however, the U.S. became fully committted to the LWRLMFBR scenario based on use of plutonium fuel, and U.S. work on the idea was dropped. However, basic features of the conicept have been carried forward elsewhere, so that many of the essential engineering questions bearing on feasibility have now been resolved and solutions demonstrated in operating plants. 
The collection of NASAP reports, resulting from various DOE projects, should provide useful data on which judgments concerning the merits of different paths for nuclear power development can presumably be made. Such judgments are the goal of an international effort (INFCE) to address all of the issues affecting nuclear power development in an integrated and coherent manner. In proposing the International Fuel Cycle Evaluation (INFCE), it is recognized that nuclear power will be needed by many countries to meet anticipated energy needs, and that the uranium resources in and available to these countries are limited. Nuclear power planning in most countries. has been based on the near-term use of light-water reactors and the utilization of the plutonium-fueled fast-breeder reactor in the longer term. A major goal of INFCE is to explore proliferation-resistant alternate reactor concepts and fuel cycles which potentially improve uranium resource utilization to the point that the recovery and use of plutonium and the deployment of the plutonium-fueled breeder reactor would be either unnecessary, or could at least be delayed sufficiently far into the future that effective technical and institutional safeguards can be developed. For these alternatives to be accepted on a significant scale and deployed internationally, they would need to be technically and environmentally sound, economic and commercially feasible. As a natural outgrowth of the LWR system, the SSCR meets most of the requirements for acceptance. The major question which remains at the conclusion of this study is whether or not the fuel savings, in the cycles of practical interest, are large enough to induce the effort and investment on the part of industry. necessary to attain commercial choice of the concept. 
The spectral shift controlled reactor (SSCR) consists basically of a standard pressurized water reactor (PWR) plant in which the conventional soluble boron reactivity control system is replaced with spectral shift control. In the conventional PWR, lifetime reactivity control is achieved through the introduction of soluble boron into the reactor coolant to capture the excess neutrons generated throughout plant life. The soluble boron concentration is gradually reduced during the operating cycle by the introduction of pure water to compensate for the depletion of fissile inventory and the buildup of fission product poisons. In the spectral shift controlled reactor, the excess reactivity control is achieved by the addition of heavy water to the reactor coolant which shifts the neutron spectrum present in the reactor to higher energies, and results in the preferential absorption of neutrons in fertile material. In contrast to operation of the conventional PWR where absorptions in control poisons are unproductive, the absorption of excess neutrons in fertile material breeds additional fissile material (either plutonium or U-233, depending on whether the uranium or thorium fuel cycle is employed), increasing the conversion ratio of the system. As a result of the increased production of fissile material, the annual demand for $\mathrm{U}_{3} \mathrm{O}_{8}$ and SWU are both reduced.

A more specific idea of how the main SSCR fuel characteristics compare with those of the PWR can be gained from the changes in fissile inventories and consumptions for an equilibrium once-through uranium fuel cycle using three batches and $30 \mathrm{GWd} / \mathrm{t}$ discharge exposure. The net effect of the heavy- 
water-induced shift of the neutron spectrum is to increase the production of fissile from fertile material during the cycle $(+3.5 \mathrm{~kg} / \mathrm{t}$ out of 24.1$)$, increase the consumption of converted fuel $(+2.4 \mathrm{~kg} / \mathrm{t}$ out of 17.8$)$, reduce the required initial fuel enrichment $(-2.5 \mathrm{~kg} / \mathrm{t}$ out of 29.5$)$ and increase the residue of converted fissile material in the spent fuel $(+1.2 \mathrm{~kg} / \mathrm{t}$ out of 6.3). The combination of these changes results in an ore demand reduction of $11 \%$ in the equilibrium cycle.

The differences between PWR and SSCR are most apparent in single-batch cores where the initial reactivity is high, requiring large concentrations of boron or heavy water at beginning of cycle. For the conventional threebatch fuel management, the differences become less pronounced and the maximum equilibrium operating heavy water concentration is typically as low as $40 \mathrm{wt} \%$. As the number of batches is further increased, the fueling differences between PWR and SSCR become progressively smaller and, of course, vanish in the limit of on-line refueling because no heavy water would be required to control excess reactivity.

In the design of the SSCR plant, a number of equipment changes are required to permit controlled variation of the heavy-to-light-water ratio in the coolant, refueling with limited $\mathrm{D}_{2} \mathrm{O}$ loss and tritium exposure of personnel in the containment, and upgrading of the heavy water diluted with light water during the operating cycle. The last item requires large vacuum distillation columns heated by reactor steam, similar to those installed in Candu plants, to enrich the heavy water inventory to the level necessary for start of the next cycle. The control of the hydrogen/deuterium ratio 
is achieved by a modified Chemical and Volume Control System (CVCS) with additional tankage for enriched $\mathrm{D}_{2} \mathrm{O}$ and diluted coolant awaiting distillation. The refueling procedure is also modified to allow refueling to take place in essentially pure berated light water. Beyond these major system changes there are many detailed changes in specification of pumps, valves and coolant leakage pickup systems to minimize loss of heavy water from the primary system and control tritium levels inside containment. In all, these equipment changes are estimated to cost 26 million dollars and add about $0.38 \mathrm{mills} / \mathrm{kWh}$ to the capital costs of a large SSCR. Additionally, the operation and maintenance costs are estimated to be about 0.1 mills/kWh higher for the SSCR than for the conventional PWR due to the added complexity of performing maintenance on tritium containing systems.

2-6 
The spectral shift controlled reactor is unique among the alternate reactor systems being considered in NASAP because of its use of the pressurized light-water reactor nuclear steam-supply system. This relationship with the LWR brings to the SSCR not only marked advantages but some disadvantages as well relative to other alternatives. Although SSCR demand for $\mathrm{U}_{3} \mathrm{O}_{8}$ and SWU is below that of the conventional LWR, particularly when fuel is recycled, the basic properties of light water and lack of on-line refueling limit the fuel utilization efficiency of the SSCR to lower levels than that achievable in such alternatives as the Candu reactor. On the other hand, the prospect of early and wide-spread deployment of the SSCR is significantly better than for new alternate advanced converter systems because it is basically founded on PWR technology and built of PWR components. Thus, although the inherent resource utilization of an individual SSCR plant may be less attractive than that of other alternatives, the SSCR could result in a more significant reduction in overall system $U_{3} O_{8}$ and SWU demand than might be achieved with other alternatives simply because of this potential for more rapid acceptance and deployment.

The prospects for adoption of the SSCR are also enhanced by the low risk inherent in the concept. Since the SSCR could always be operated, if need be, in the conventional poison-control mode, there would be no risk to station generating capacity if the SSCR were employed, and the financial risk would be limited to the cost of the additional equipment required to realize spectral-shift control, which is estimated to be about $4 \%$ of the 
total cost of the plant. The risk, both to capital and generating capacity, is probably lower than for many other alternate reactor systems.

It may prove feasible to backfit spectral-shift control into existing pressurized-water reactors or designs if more detailed evaluations were to justify this course of action. This could occur at one of two stages namely in plants still in early construction stages in the early 80 s and, with much lower probability, in. some completed plants where the layout favors modification. However, it must be admitted that in most cases, even when judged feasible, the benefits of backfitting would have to be great indeed to justify the idle plant costs during modification (i.e., the replacement power costs).

Based on the economic evaluations made during this study, a power cost advantage would not be expected for the SSCR until ore prices reached about $\$ 100 / 1 \mathrm{~b} \mathrm{U} \mathrm{U}_{3} \mathrm{O}_{8}$. The SSCR fuel cycle costs including the $\mathrm{D}_{2} 0$ inventory and makeup, are lower than those of the PWR even in the once-through cycle, but the additional equipment costs, estimated at 26 million dollars, when added to an increased operating and maintenance cost overbalance the fue 1 cost savings at present-day ore costs. Any economic incentive to employ the SSCR concept would appear to lie well into the future and depends on the relative inflation of various cost components. Furthermore, the potential benefit of deploying the SSCR must be balanced by the fact that a large number of LWRs would already be operating before this concept would be introduced. 
Initial work on the SSCR concept was performed in the U.S. under AEC auspices in the early 1960 period $^{\prime}$, and the aim at the time was to design a demonstration plant for construction in the mid-sixties, preferably for eventual operation on the thorium cycle. Fuel management studies showed that the initial inventory and consumption of the fissile material could be reduced by $25 \%$ and $50 \%$, respectively, relative to poison control in reactors fueled with highly-enriched U-235 in thorium oxide. The performance of the uranium-plutonium cycle was not expected to benefit as much from spectralshift control as the thorium cycle, but a reduction of $25 \%$ in uranium ore requirements projected for the U-Pu cycle was viewed, nonetheless, as a compelling inducement to develop and demonstrate the concept as an advanced converter. However, by 1965 the U.S. government policy, as implemented in AEC programs, had changed to emphasize the LWR for immediate commercial application and the LMFBR for the longer term development of nuclear power to the exclusion of most other reactor systems. In addition, both uranium ore and separative work were relatively inexpensive, plutonium recycle was planned to reduce LWR ore demand in the immediate future and fuel resource conservation was not recognized as having the importance that it has today. In this atmosphere, advanced converter reactors or fuel cycles held little attraction for commercial development.

Interest in the SSCR concept, continued outside the U.S. after AEC abandonment, and a demonstration of the engineering feasibility was carried out by 
the Vulcain experiment in the BR-3 nuclear plant at Mol, Belgium ${ }^{2}$. The BR-3 plant, after two years of operation as a conventional PWR, was modified for spectral-shift control and operated successfully in this way between 1966 and 1968. The Vulcain core attained a core-averaged burnup of 23,000 $M W d / t$, a peak burnup of about $50,000 \mathrm{MWd} / \mathrm{t}$ and achieved an average load factor and primary plant availability factor of 91.2 and $98.6 \%$, respectively. The leakage rate of primary water from the high-pressure reactor system to the atmosphere was found to be negligible, at about $30 \mathrm{~kg}$ of $\mathrm{D}_{2} \mathrm{O} / \mathrm{H}_{2} \mathrm{O}$ mixture per year ${ }^{3}$. After completion of the Vulcain experiment, the BR-3 plant was returned to normal PWR operation for other experimental programs. The Vulcain experiment thus demonstrated on a small plant both the spectralshift concept and the feasibility of converting an existing plant to this mode of reactivity control.

The successful solution of the engineering problem of containing $\mathrm{D}_{2} \mathrm{O}$ with a very small leak rate has also been demonstrated in a pressure vessel type PWR design by the $340 \mathrm{MW}(\mathrm{e})$ Atucha plant built in Argentina by Kraftwerk Union $^{4}$. The configuration of the plant is essentially that of a PWR except that an on-line refueling machine is provided to allow the use of natural uranium fue 1, and the moderator and coolant volumes within the pressure vessel are cooled by separate primary loops. By careful attention to the design of pumps, valves, component layout and recovery system, the annual leakage rate of $D_{2} 0$ has been held to about $0.5 \%$ of the $D_{2} 0$ inventory. The Atucha design is relevant to the SSCR in demonstrating the feasibility of constructing a PWR primary system which provides adequate containment of $\mathrm{D}_{2} \mathrm{O}$ and tritium under operating conditions. 


\section{REFERENCES FOR SECTION 2}

"Introduction"

1. M. C. Edlund, "Developments in Spectral Shift Reactors," Proc. Third U.N. Conf. on Peaceful Uses of Atomic Energy, $\underline{6}, 314$ (1964).

2. J. Storrer, "Experience with the Construction and Operation of the BR3/Vulcain Experiment," Symposium of Heavy Water Power Reactors, IAEA, Vienna, September 11-15, 1967.

3. J. Storrer, et al., "Belgonucleaire and Siemens PWRs for Small and Medium Power Reactors," Proc. Symp. on Small and Medium Power Reactors, IAEA, 0s10, October 12-16, 1970.

4. G. Herzog and K. J. Sauerwald, "Atucha Nuclear Power Station, A Natural Uranium PHWR in the Argentine," Nucl. Eng. Int., 14, No. 157, 485 (1969). 


\subsection{SUMMARY DESCRIPTION OF SSCR}

\subsubsection{DESIGN APPROACH}

The conceptual design of the SSCR is based on Combustion Engineering's System $80^{\mathrm{TM}} 3800 \mathrm{MW}(\mathrm{th}) \mathrm{PWR}^{\mathrm{T}}$ and Stone \& Webster's $1300 \mathrm{MW}(\mathrm{e})$ Reference Nuclear Power Plant ${ }^{2}$. It was developed by modifying and/or adding equipment for spectral shift control operation to the standard plant systems. While developing the SSCR conceptual design, the capability of the plant was retained to resume operation with conventional poison control essentially without hardware changes.

The major performance parameters of the SSCR are listed in Table 3.1.1-1 
TABLE 3.1.1-1

\section{GENERAL REACTOR PERFORMANCE PARAMETERS}

A. Power Plant Performance

Core Thermal Power (MW)

NSSS Thermal Power (MW)

Electrical Power (MWe)

Gross

1335.5

Net

1258

Thermal Efficiency

B. Reactor Parameters

Core Volume (iiters)

40,050

Core Dimensions

Equivalent Diameter (m)

3.66

Active Length (m)

3.81

Core Power Density (MW/ $\ell$ )

0.095

Coolant Flow Rate $(\mathrm{Mg} / \mathrm{sec})$

20.66

Coolant Inlet Temperature $\left({ }^{\circ} \mathrm{C}\right)$

296

Coolant Outlet Temperature $\left({ }^{\circ} \mathrm{C}\right)$

327

Primary System Pressure (bar)

155

C. Fuel Parameters

Average Fuel Temperature $\left({ }^{\circ} \mathrm{C}\right)$

688

Maximum Fue 1 Temperature $\left({ }^{\circ} \mathrm{C}\right)$

1882

Cladding Temperature $\left({ }^{\circ} \mathrm{C}\right)$

Core Fuel Loading $(\mathrm{kg})$

$\mathrm{UO}_{2}$ Core Total Heavy Metal

102,775

$\mathrm{ThO}_{2}$ Core Total Heavy Metal

93,555

Discharged Exposure (MWd/t)

$\mathrm{UO}_{2}$ Core (Nominal)

30,400

$\mathrm{UO}_{2}$ Core (Improved)

50,650

$\mathrm{ThO}_{2}$ Core

33,400

Fuel Stack Density $\left(\mathrm{gm} / \mathrm{cm}^{3}\right)$

$\mathrm{UO}_{2}$ Fue 1

10.054

$\mathrm{ThO}_{2}$ Fue 1

9.173 
The overall plant layout of the SSCR is shown on the plot plan, figure 3.1.2-1. It is based on the arrangement of a Stone \& Webster single unit, PWR Reference Plant.

Spectral shift operation requires some modifications and equipment additions to the plant systems of a conventional PWR. The major equipment additions are a $D_{2} \mathrm{O}$ upgrader facility, tanks for storing heavy-water mixtures and additional boron evaporators.

The $\mathrm{D}_{2} \mathrm{O}$ upgrader facility is housed in a separate building which is located nörtheast of the Solid Waste and Decontamination Building. Because it is impractical to design the three 225-foot-tall distillation towers of the upgrader to withstand tornado wind forces, the upgrader facility is located far enough away from other buildings to avoid impacting earthquake-proof (Seismic Category I) foundations in the case of a distillation tower failure. At: this location, the upgrader facility also can make maximum use of common facilities, (e.g., service building, warehouse, etc.) in the event a second plant is built at the same site. The upgrader building is designed with an earthquake-resistant foundation which is sized to be capable of retaining the water inventory of the facility.

The basic approach in arranging the additional storage tanks and boron evaporators was to minimize changes to safety-related equipment (e.g., engineered safeguards systems) layout, thereby minimizing perturbations of the layout of the PWR Reference Plant which might impact the licensing of 
the SSCR. Because the additional tanks store various concentrations of heavy water, they are located in the Annulus Building which is an earthquakeproof (Seismic Category I) and tornado-protected structure. A number of these tanks are designed as cubicles with stainless steel liners in order to use available space most effectively.

The additional boron evaporators and some of the equipment which was displaced from the Annulus Building by the additional storage tanks were relocated in the Solid Waste and Decontamination Building necessitating enlargement of this building.

The two Light Water Storage Tanks in the tank yard area adjacent to the evaporator area in the Solid Waste and Decontamination Building are the renamed Primary Grade Water Tanks of the conventional PWR design. They are used to store the $\mathrm{D}_{2} \mathrm{O}-\mathrm{lean}$ overhead stream from the upgrader facility.

\subsubsection{CORE DESIGN}

The optimization study of the core configuration (which is described in

more detail in Section 4) showed that the System $80^{T M}$ core geometry is a good choice for spectral shift operation with either uranium or thorium fueling. Thus, the unmodified Systein $80^{\mathrm{TM}}$ core geometry, reactor vesse 1 and vessel internals were retained for the SSCR.

The reactor core consists of 247 fuel assemblies and 89 control element assemblies. The fuel assemblies are arranged to approximate a right 
circular cylinder with an equivalent diameter of 143 inches and an active length of 150 inches. A core cross section and the geometry of the fuel assemblies are shown in Figure 3.1.3-1. The basic structure of the fuel assembly consists of five large zircaloy guide tubes which are connected by common lower and upper end fittings. Four guide tubes provide channels to guide the control elements over their entire length of travel. The fifth guide tube is located in the center of a fuel assembly and, in the instrumented assemblies, contains the in-core instrumentation.

The reactor vessel contains the core as well as the core internals which support and orient the fuel and control element assemblies. The core internals also guide the reactor coolant through the reactor vessel. A plan view of the vessel and its internals is shown in figure $3.1 .3-2$.

The SSCR can be fueled with either $\mathrm{UO}_{2}-$ or $\mathrm{ThO}_{2}$-based fuels; the bas is reactor and BOP design is compatible with either fuel type, without modification. The fuel rod design is identical to that of System $80^{\mathrm{TM}}$ if the SSCR is operated consistent with the present PWR fuel management strategy ( 3 fuel batches; $30,400 \mathrm{MWd} / \mathrm{t}$ batch-average discharge exposure). The fuel is in the form of ceramic pellets contained in hermetically-sealed prepressurized zircaloy tubes. Fuel pellets of 0.325 in. 0.D. are stacked to an active core height of $150 \mathrm{in.}$ within the zircaloy fuel tube, which is of 0.382 in. 0.D. and 0.025 in. wall thickness.

Uranium resource as well as fuel cycle cost savings can be made in the SSCR (as well as in the conventional PWR) for the $\mathrm{UO}_{2}$ once-through fuel cycle by 

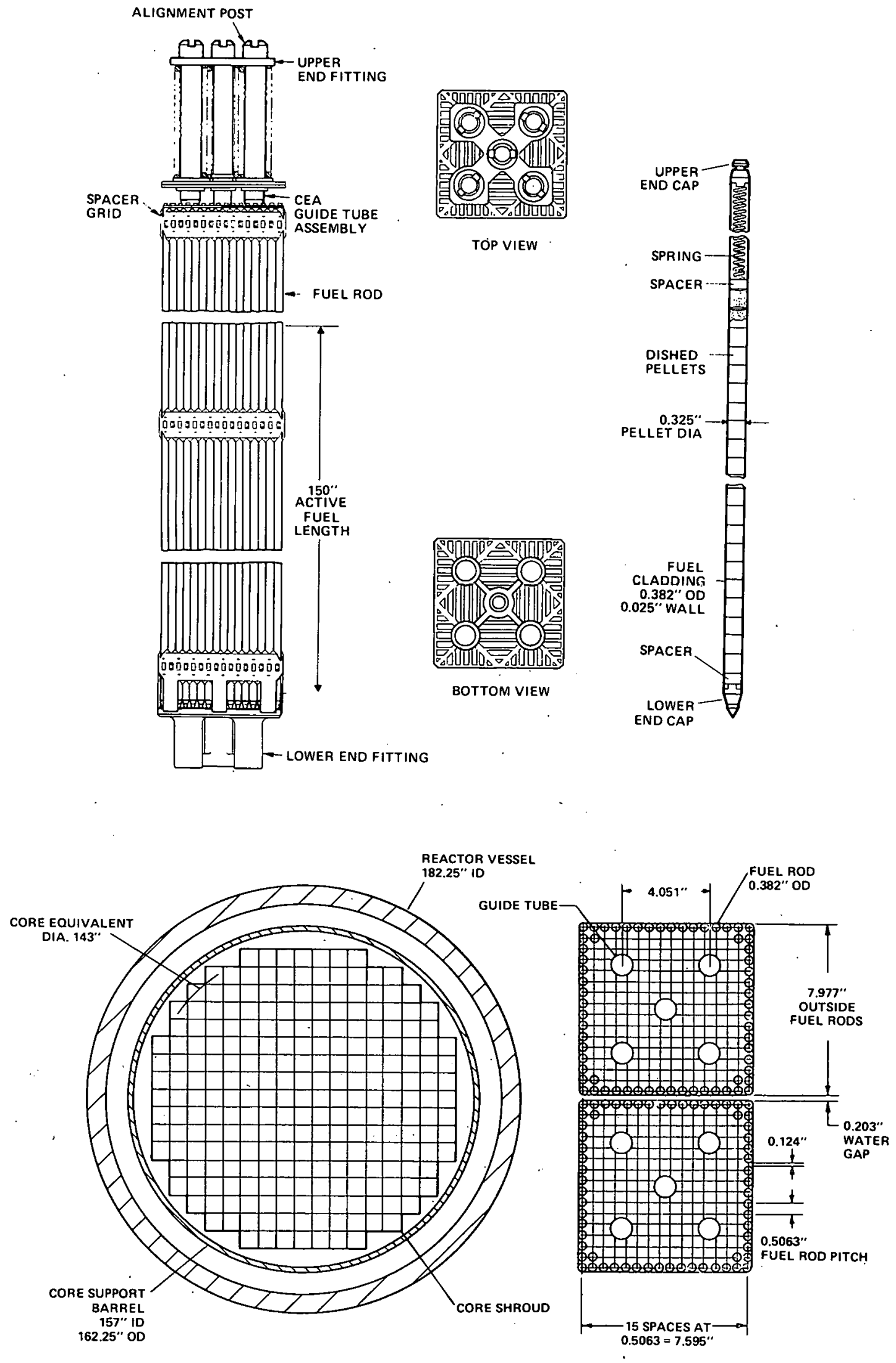

Figure 3.1.3-1

REACTOR CORE CROSS SECTION 


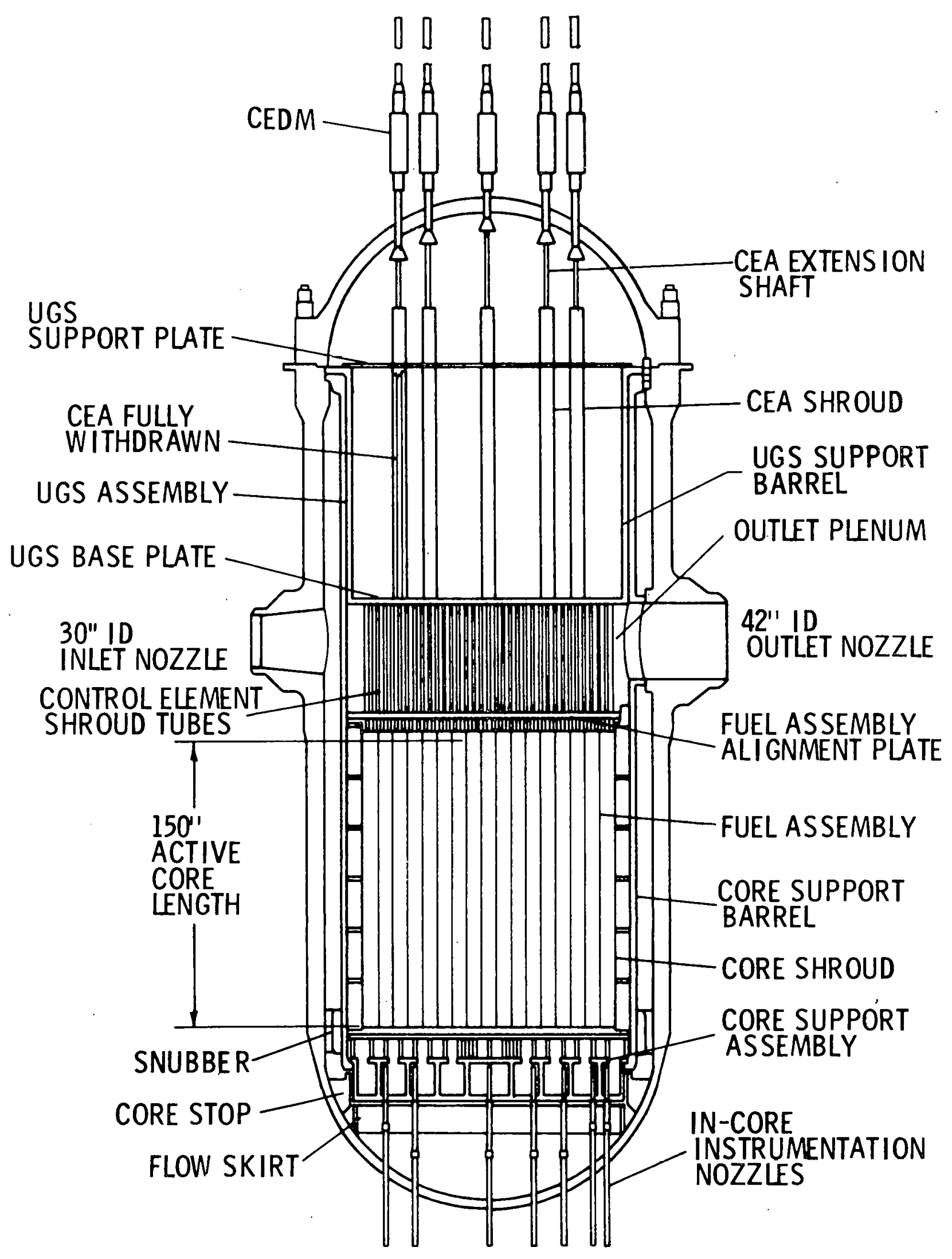

Figure 3.1.3-2

REACTOR. VERTICAL ARRANGEMENT 
increasing the number of refueling batches and extending the batch-average burnup to about $50,000 \mathrm{MWd} / \mathrm{t}$. This results in maximum fuel rod average burnups of about $62,000 \mathrm{MWd} / \mathrm{t}$. Rod average burnups of this magnitude are about $65 \%$ higher than the burnups reached presently in PWRs. A fuel rod design for the extended burnups must address several technical problem areas, e.g., the higher percentage release of fission gases at higher burnups, corrosion of the outside surface of the cladding, pellet-clad interaction and structural stability (elongation and bowing of rods). At present, it appears that accomodation of the fission gases without increasing the internal pressure on the fuel tube beyond design limits will pose the most difficult problem. Figure 3.1.4-1 summarizes the results of a parameter study and shows that there are several design options (annular pellets, shorter fuel stacks, longer fuel tubes, higher internal pressure limits) which, either alone or in combination with each other, could be taken to develop a high burnup fuel rod design. Due to the large uncertainties associated with predicting fission gas release, it is considered premature to settle now on a specific design before in-pile testing of various fuel rod designs provides a more substantive basis for the choice.

\subsubsection{PRIMARY COOLANT SYSTEM}

The main components of the reactor coolant system (steam generators, main coolant piping and basic design of the main coolant pumps) remain unchanged from the System $80^{T M}$ design, which is a modified two-coolant-loop plant with two hot legs and two U-tube steam generators as well as four cold legs with four main coolant pumps. 


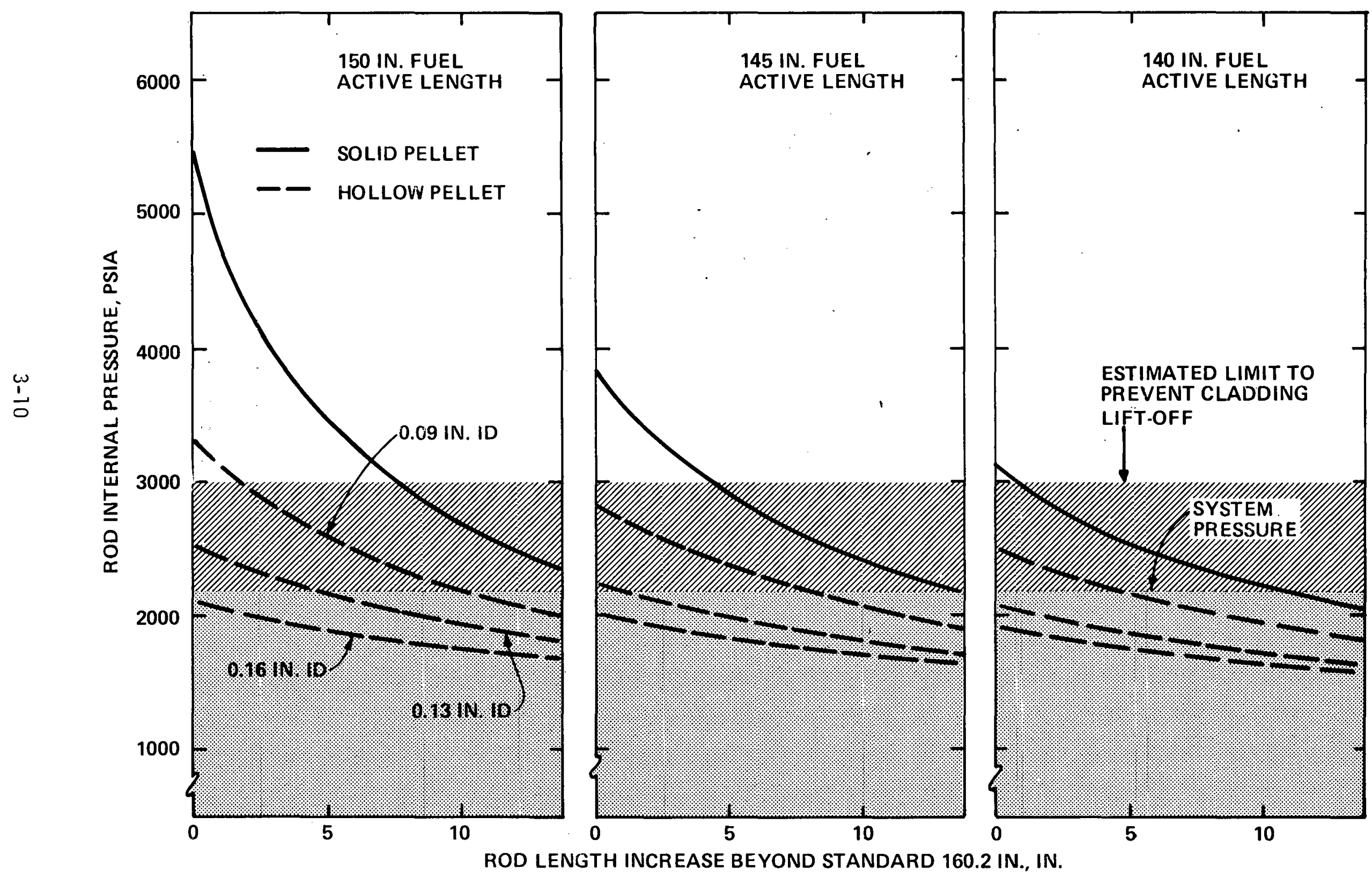

FIGURE 3.1.4-1

FISSION GAS ACCOMODATION - FUEL ROD INTERNAL PRESSURE VS. FUEL ROD GEOMETRY 
A supplementary shaft seal is added outboard of the conventional shaft seals of the reactor coolant pumps. This seal design has been used on primary coolant pumps for CANDU heavy water reactors and its purpose is to eliminate leakage of coolant to the containment atmosphere. 
Reactor operation with spectral shift control requires $\mathrm{D}_{2} 0$ addition to the coolant. $D_{2} \mathrm{O}$ is very expensive (about $\$ 80 / 1 \mathrm{~b}$ ) and radiologically hazardous due to the tritium generated during reactor operation (up to $1100 \mu \mathrm{Ci} / \mathrm{Cc}$ $D_{2} 0$ ). Thus, minimizing $D_{2} 0$ inventory as well as $D_{2} 0$ leakage and losses is a major consideration for the design of plant fluid systems.

At the beginning of a cycle, the $\mathrm{D}_{2} \mathrm{O}$ concentration in the reactor coolant is a maximum of about $60 \mathrm{wt} \%$ and decreases approximately linearly over the cycle to 2 wt\%. The $D_{2} 0$ concentration reduction is accomplished by bleeding coolant from the primary system via the standard letdown line for coolant purification and feeding light water into the coolant system via the standard volume control tank and charging pumps. The bled coolant is piped to storage tanks and, ultimately, to the $D_{2} 0$ upgrader where the heavy water is separated from the light water for later reuse.

Although the presence of $\mathrm{D}_{2} \mathrm{O}$ in the coolant obviates the need for suppression of the excess reactivity by boron addition during normal power operation, boron is still needed for refueling shutdowns. In order to maximize the benefit from spectral shift operation, boron is removed from the primary system after refueling as quickly as the feed flow of the charging pumps (about $135 \mathrm{gpm}$ ) permits. Increasing the boron separator capacity to the charging pump capacity eliminates the storage of large quantities of $\mathrm{D}_{2} \mathrm{O}^{-}$ containing coolant prior to deboration, and thus minimizes the overa $\mathrm{D}_{2} \mathrm{O}$ inventory. 
In order to accomplish the adjustment of the $\mathrm{D}_{2} \mathrm{O}$ and boron concentration in the coolant, modifications and/or equipment additions to several plant systems of a convential PWR are necessary. These systems are the Boron Recovery System (BRS), the Primary Grade Water System (PGWS), and the Chemical and Volume Control System (CVCS). Figure 3.1.6-1 shows a simplified composite diagram of the unmodified systems as used in a PWR, while Figure 3.1.6-2 shows these systems modified for spectral shift operation.

In the following paragraphs, the major equipment modifications or additions to the PWR systems are described in more detail, while the $D_{2} 0$ upgrader is described in Section 3.1.7.

\subsubsection{Holdup Tanks}

The two holdup tanks (approximately 35,000 gallons each) provide for temporary storage (prior to processing) of letdown bleed produced by dilution of the heavy water concentration of the Reactor Coolant System (RCS) during the core cycle and by boration prior to shutdowns. The purpose of these tanks is comparable to the boron recovery tanks of a PWR (two tanks at 150,000 gallons each). The capacity is less for the SSCR holdup tanks as additional required capacity for letdown water is provided by the RCS Loop Drain Tank and the PGWS letdown tanks as described below.

\subsubsection{RCS Loop Drain Tank}

The purpose of this additional tank is to store water drained from the RCS prior to refueling. In the PWR design, the capacity of the boron recovery 


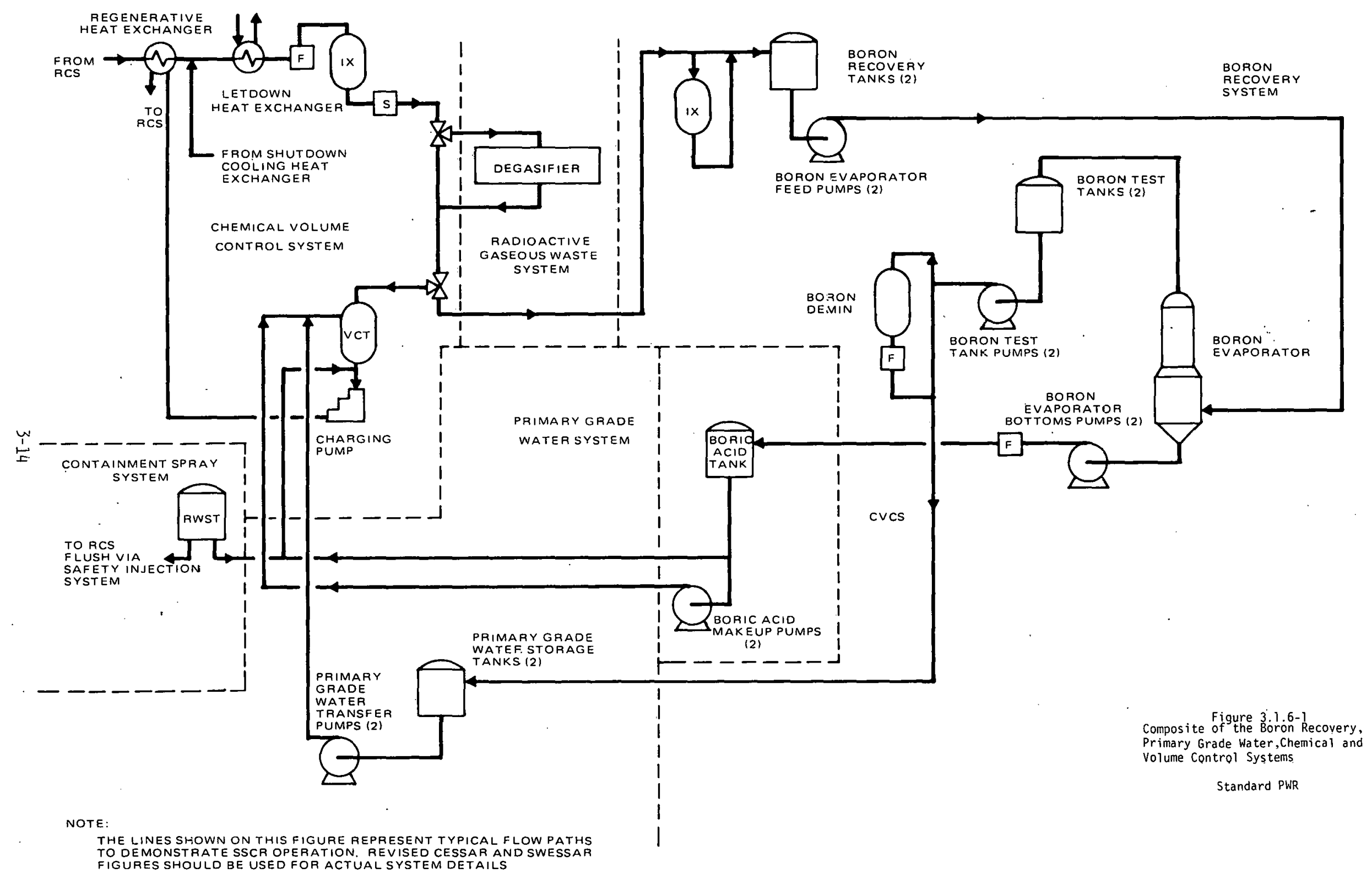




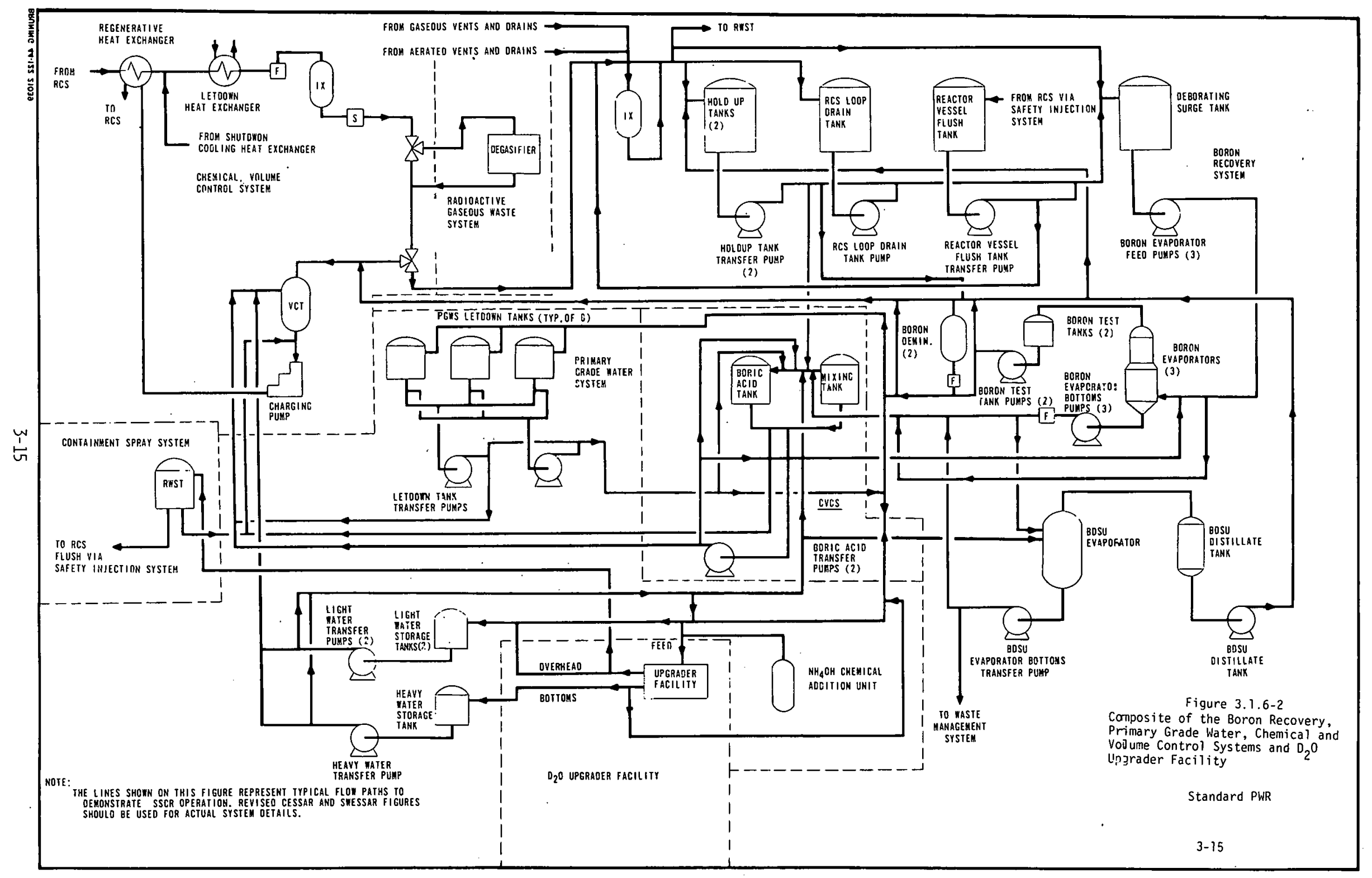


tanks provides for this. A separate tank for the SSCR is provided because (1) the RCS is drained further for the SSCR design, requiring greater capacity for this operation (see Section 3.1.8). and (2) separation of borated drain water from unborated letdown bleed minimizes borón evaporator operation. The capacity of this tank is approximately 80,000 gallons.

\subsubsection{Reactor Vessel Flush Tank}

The reactor vessel flush tank has been added to the SSCR design to provide storage volume for water generated by the flushing operation that is used prior to refueling (see Section 3.1.8). The capacity of this tank is approximately 90,000 gallons:

\section{1 .6 .4}

\section{Boron Evaporators}

Three boron evaporators (45 gpm each) have replaced the one $25 \mathrm{gpm}$ boron. evaporator used in the PWR design. As mentioned before, the capacity of the three boron evaporators matches the capacity of the charging pumps and permits on-line deboration without generation of large water volumes which need to be stored before being processed through smaller capacity evaporators.

The boron separators also serve the purpose of removing boron from any water which is to be upgraded in the $D_{2} 0$ upgrader, because the upgrader requires feed free of boric acid. 


\section{1 .6 .5}

Boric $A c i d / D_{2} O$ Separation Unit (BDSU)

This separation unit has been added to the SSCR design in order to extract the heavy water/light water mixture from the boric acid in the boron evaporators bottoms. This is necessary to avoid loss of $D_{2} 0$. This unit contains an evaporator, a distillate tank and pump, and an evaporator bottoms pump. The capacity of the unit is $1150 \mathrm{gpd}$.

\subsubsection{Letdown Tanks}

The purpose of the eight letdown tanks is to store boron-free $\mathrm{D}_{2} \mathrm{O} / \mathrm{H}_{2} \mathrm{O}$ mixtures. These fluid volumes might be bled directly from the reactor coolant system or might be volumes which have been processed through the boron evaporators and stored prior to processing in the $D_{2} 0$ upgrader. $\mathrm{D}_{2} \mathrm{O} / \mathrm{H}_{2} \mathrm{O}$ mixtures with low $\mathrm{D}_{2} \mathrm{O}$ concentration are reused as dilution feed at the beginning of a cycle when the coolant $D_{2} \mathrm{O}$ concentration is high while mixtures with high $D_{2} 0$ concentrations will be transferred to the $D_{2} 0$ upgrader for processing. In both cases, boron-free material is required. If the coolant is to be used as feed material for the RCS, it must be as free of boron as possible since the RCS contains no boron during normal operation. If the coolant is to be used as feed material for the upgrader, then it must be deborated since the distillation process requires feed free of boron (which is in the form of boric acid).

The reason for arranging eight 35,000-gallon tanks is more economic space utilization. Also, the use of eight tanks provides the capability to store water of approximately reactor coolant $\mathrm{D}_{2} \mathrm{O}$ concentration for boration and makeup of contraction volume in the event of a cold shutdown anytime during the core cycle. 


\subsubsection{Mixing Tank}

In the SSCR design shutdown boration and contraction volume makeup are accomplished without changing the $\mathrm{D}_{2} 0$ concentration in the RCS existing at the time of shutdown. The mixing tank has been added so that the volume of coolant necessary to borate the RCS and to provide for contraction during cooldown can be premixed. The capacity of the tank is approximately 35,000 gallons.

\subsubsection{Light Water Storage Tanks}

The two primary grade water storage tanks of the PWR design are used as light water storage tanks for the SSCR. They store overhead from the upgrader facility ( 1 ight water at $0.5 \mathrm{wt} \% \mathrm{D}_{2} 0$ ). The capacity of the tanks is the same as when used for the PWR $(100,000$ gallons each).

\subsubsection{Heavy Water Storage Tank}

The purpose of this additional tank for the SSCR is to store the bottoms of the upgrader $\left(85 w t \% D_{2} 0\right)$. The capacity of this tank is approximately 80,000 gallons.

\subsubsection{Refueling Water Storage Tanks}

The refueling water storage tank has been increased in capacity from approximately 650,000 gallons to approximately 780,000 gallons in order to 
accommodate the flush volume necessary for the coolant exchange prior to refueling or removal of the reactor vessel head anytime during the core cycle (for a description of the coolant exchange see Section 3.1.8). 
The $\mathrm{D}_{2} \mathrm{O}$ upgrader is the only major plant system which is a unique addition to the power plant for spectral shift control: The facility processes the... coolant bled from the primary system during the bleed-and-feed operation to reduce the $\mathrm{D}_{2} \mathrm{O}$ concentration in the coolant. It separates the heavy from the light water and produces enough coolant of high $D_{2} 0$ concentration for subsequent core cycles. In addition, the facility will also be needed to upgrade spilled and otherwise diluted coolant. Upgrader units of similar design are in operation in the Canadian Candu heavy water reactor power stations and are used to upgrade coolant which becomes accidentally diluted during plant operation to reactor grade $D_{2} 0$ concentration.

The separation of heavy from light water in the $\mathrm{D}_{2} \mathrm{O}$ upgrader is accomplished by multiple fractional distillation, which utilizes the fact that the boiling temperature of heavy water is slightly higher than that of light water. The boiling point difference becomes relatively larger at sub-atmospheric pressure (about $3^{\circ} \mathrm{F}$ ); therefore, the distillation is carried out under vaccuum (between $100 \mathrm{~mm} \mathrm{Hg}$ and $560 \mathrm{~mm} \mathrm{Hg}$ ). The process is accomplished in three distillation towers of about $7 \mathrm{ft}$. diameter and $225 \mathrm{ft}$. height.

The $\mathrm{D}_{2} \mathrm{O}$ upgrader is designed for a $\mathrm{D}_{2} \mathrm{O}$ concentration between $60 \mathrm{wt} \%$ and 2 wt\% in the feed stream during normal operation. The upgrader separates the feed stream into a bottoms stream of $85 w t \% D_{2} 0$ concentration and an overhead 


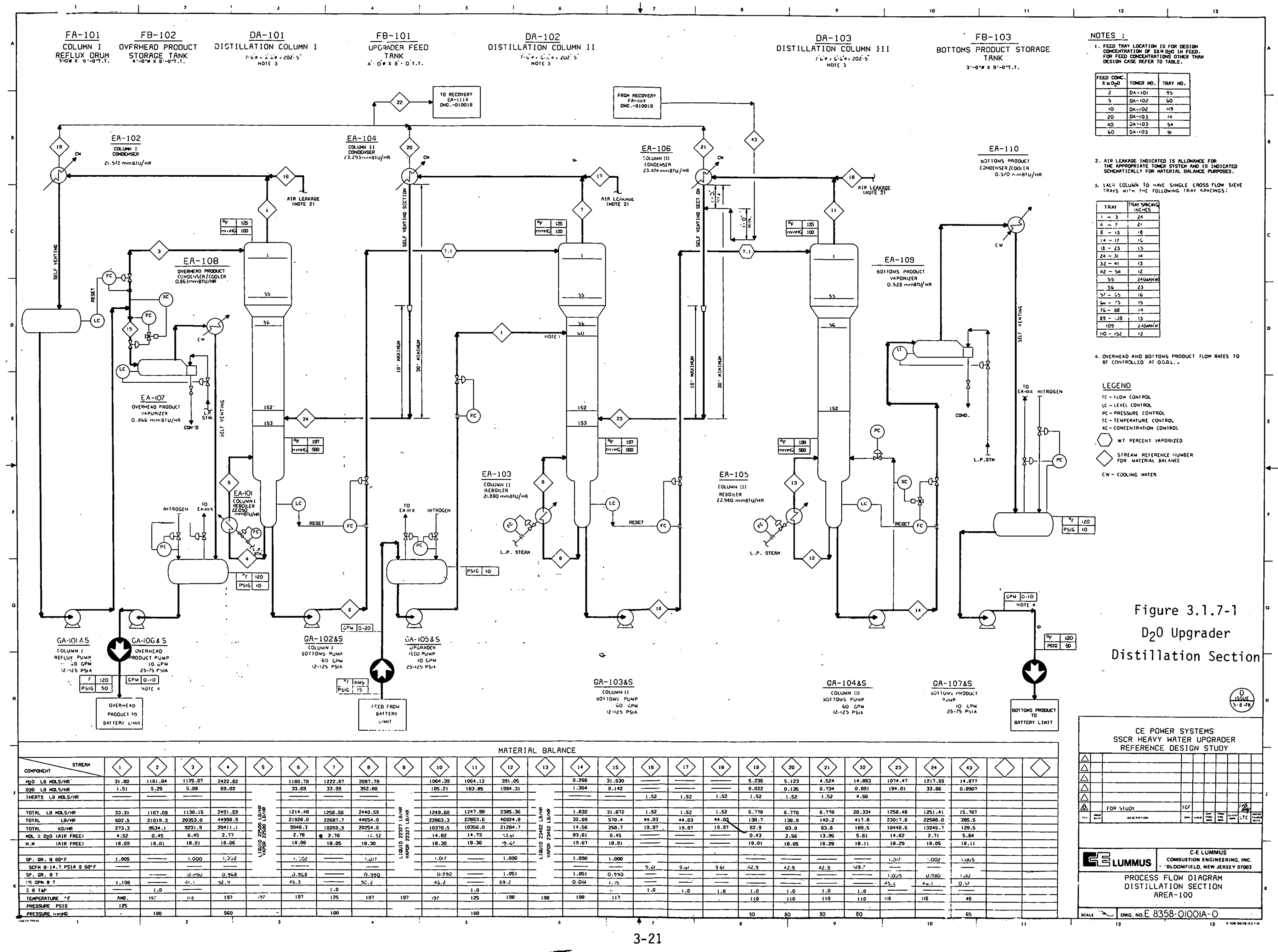



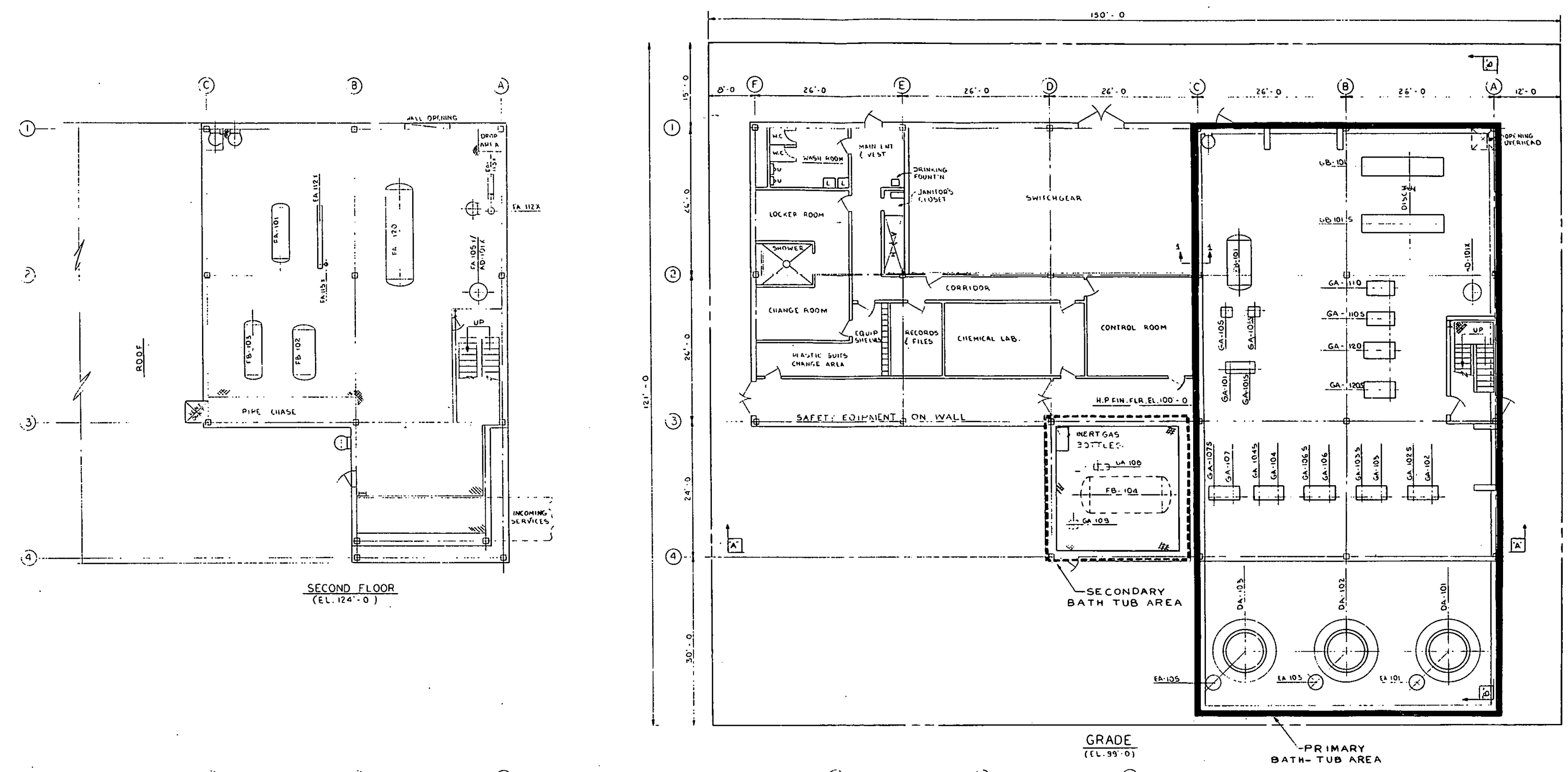

0
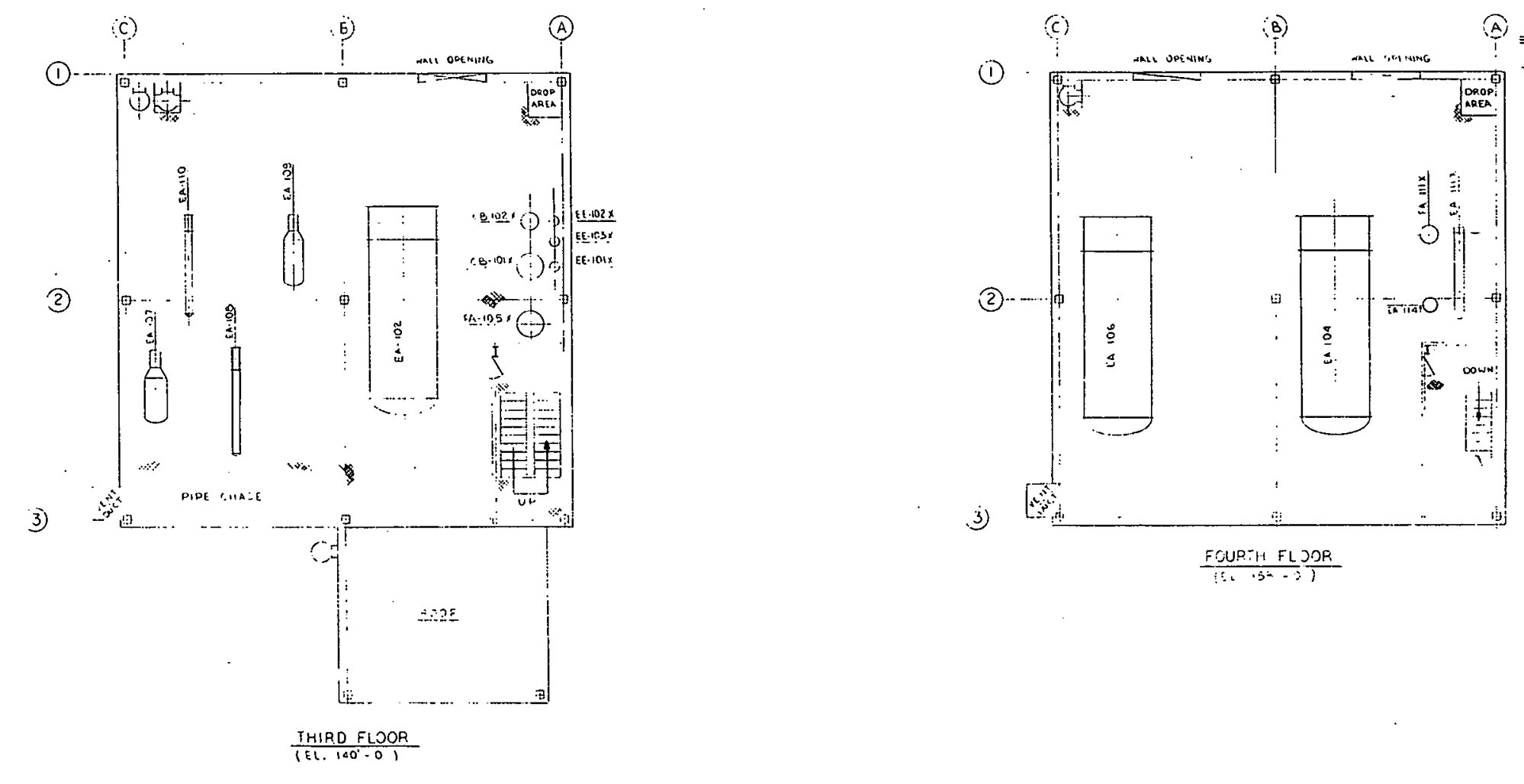

Figure 2.1.7-3 $\mathrm{D}_{2} \mathrm{O}$ Upgrader Facility

Floor Plan

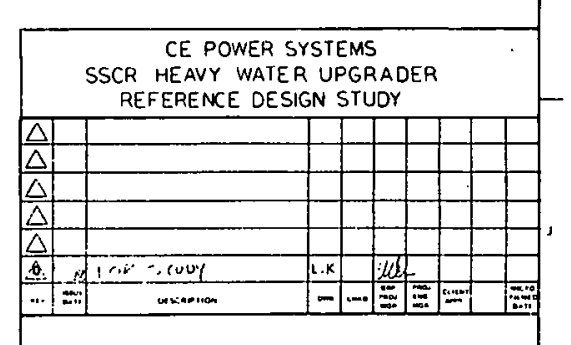

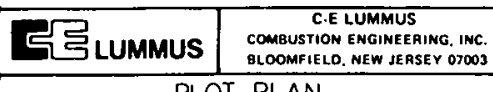

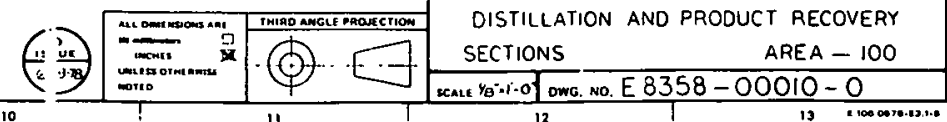




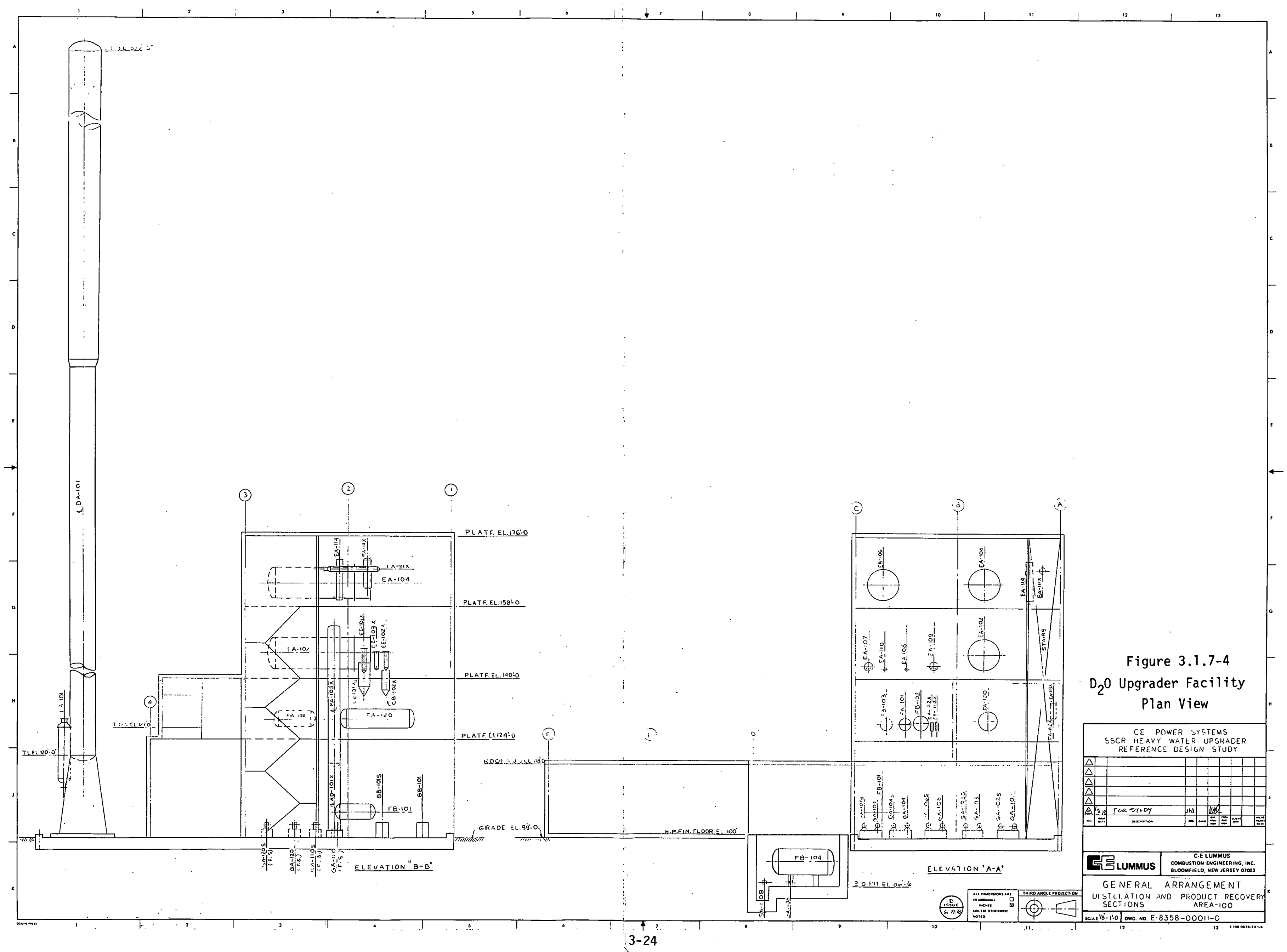


stream of $0.5 \mathrm{wt} \% \mathrm{D}_{2} 0$ concentration. The design feed flow rate of the upgrader is 1725 gallons/day. A flow schematic of the distillation towers and associated equipment is shown in Figure 3.1.7-1. Figure 3.1.7-2 represents a flow schematic of the systems to provide the vacuum for the distillation towers.

The upgrader will process about 340,000 gallons of liquid during a cycle. The bleed volume to accomplish a given reduction of the $\mathrm{D}_{2} 0$ concentration of the reactor coolant increases exponentially as the $D_{2} 0$ concentration decreases, and is about 30 times larger at the end of the cycle than at the beginning. The bleed volume at the beginning of a cycle is considerably smaller than the capacity of the upgrader, but outstrips it by close to an order of magnitude at the end of the cycle. The upgrader, therefore, will fall behind in processing bleed volume toward the cycle end. The unprocessed 1 iquid is stored and will be upgraded during the beginning portion of a subsequent cycle when the upgrader capacity exceeds the bleed volume. This situation also occurs during the very first cycle. Therefore, in order to have enough $\mathrm{D}_{2} \mathrm{O}$ for the beginning of the second cycle, a certain amount of $\mathrm{D}_{2} \mathrm{O}$ in excess of the coolant system inventory (about 20\%) is needed.

The upgrader facility will be arranged as a separate unit on the site. The towers stand in the open, while the rest of the equipment is housed in the upgrader building, see Figures 3.1.7-3 and 3.1.7-4. The towers, as well as the building, stand on a leak-tight foundation designed to contain any spillage from the facility. The upgrader will be operated on nuclear steam and will be shut down during the refueling interval. 
The basic PWR refueling procedure has been modified to avoid mixing the $\mathrm{D}_{2} 0$-containing (about $2 \mathrm{wt} \%$ ) water volume in the reactor vessel with the light water from the refueling water storage tank (RWST) which is used to fill the refueling pool above the reactor vessel. This eliminates loss by dilution of the expensive $\mathrm{D}_{2} \mathrm{O}$ inventory in the reactor vessel as well as limits the tritium concentration in the containment building due to evaporation of $\mathrm{D}_{2} \mathrm{O}$-containing water from the refueling pool.

Before removing the reactor vessel head, the primary system of the SSCR is drained to the level of the main coolant pipe centerlines in order to minimize the $\mathrm{D}_{2}$-containing water volume remaining in the reactor vessel. This residual coolant volume is then flushed out and replaced with borated (about $4000 \mathrm{ppm}$ boron) light water from the RWST. This coolant exchange is schematically shown in Figure 3.1.8-1. After the coolant exchange, refueling proceeds as in the PWR. After refueling, the water from the refueling pool and the primary system is drained back to the RWST until the water level in the reactor vessel is lowered to the centerline of the main coolant pipes. Then the vessel head is installed. To the residual water volume in the reactor vessel, which consists now of borated light water, the $85 \mathrm{wt} \% \mathrm{D}_{2} \mathrm{O}$-rich product from the $\mathrm{D}_{2} \mathrm{O}$ upgrader is added, resulting in a primary system inventory containing about $60 \mathrm{wt} \% \mathrm{D}_{2} \mathrm{O}$ and $1100 \mathrm{ppm}$ boron. 
Figure 3.1.8-1

SSCR-STUDY REFUELING-COOLANT EXCHANGE

- - LOWERING OF WATER LEVEL

COOLANT EXCHANGE

$\omega$
1

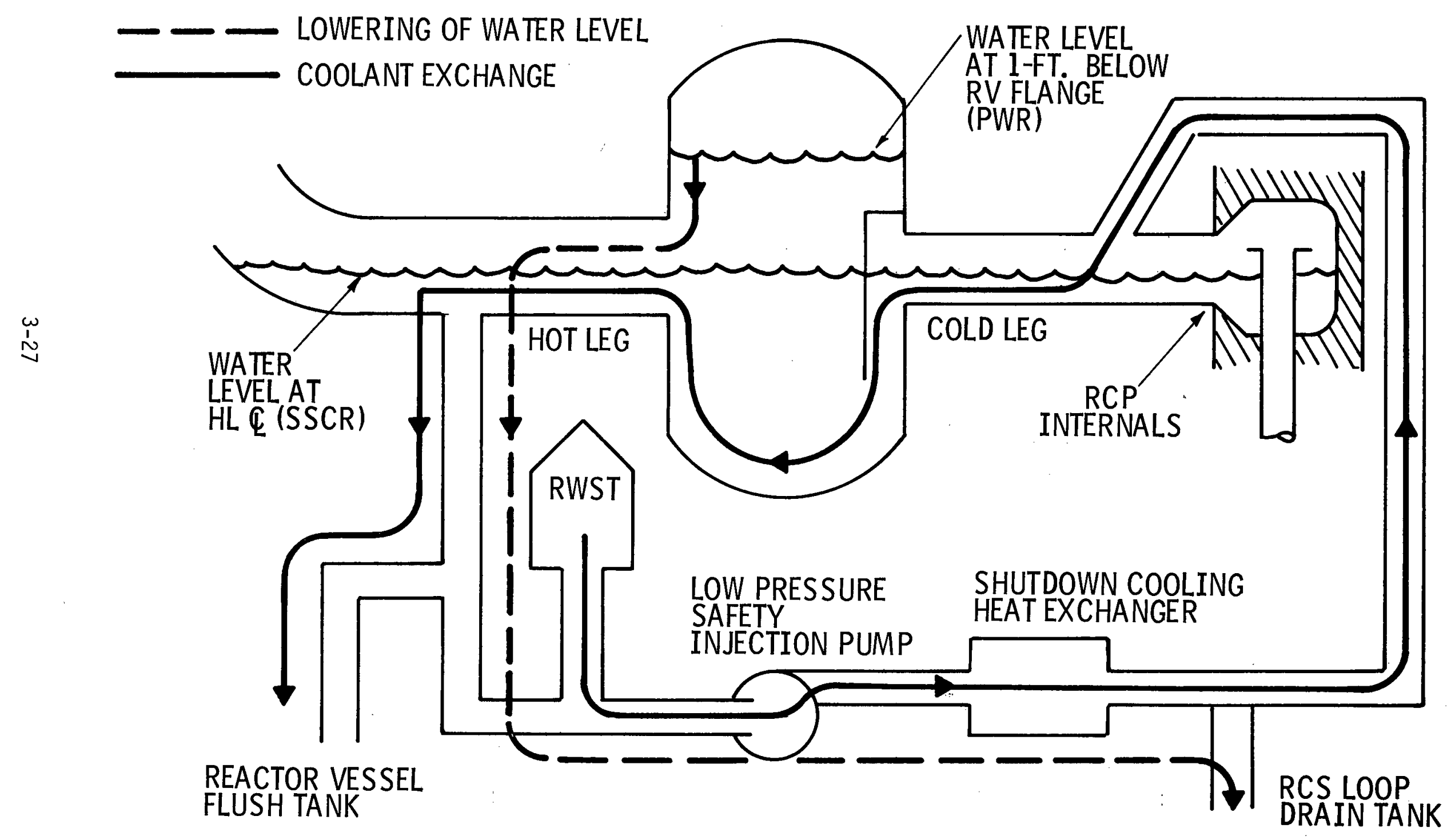


The effectiveness of the coolant exchange process requires experimental verification. For this study, it was assumed that the residual coolant is flushed via a feed-and-bleed-type process. This is conservative with respect to the fluid flow process involved and results in the largest flush volume (about 90,000 gallons).

If the RWST were replenished with the normal light water overhead stream from the $D_{2} 0$ upgrader which still contains 0.5 wt $\% D_{2} 0$, the $D_{2} 0$ concentration in the RWST at the end of the forty-year plant life, although still small, would result in a tritium dose in the containment building (via evaporation from the refueling pool surface) which would exceed the maximum permissible concentration for unlimited access. In order to keep the $\mathrm{D}_{2} \mathrm{O}$ concentration of the RWST at a sufficiently low level, it is replenished with the overhead from a special upgrader batch. For this batch, the upgrader is operated to yield an overhead of only 0.1 wt\% $D_{2} 0$ and a bottoms product of 17 $w t \% D_{2} 0$.

\section{1 .9 \\ $\mathrm{D}_{2} \mathrm{O}$ INVENTORY}

The $\mathrm{D}_{2} \mathrm{O}$ inventory required for the SSCR can be classified into two categories: operating $D_{2} \mathrm{O}$ inventory and makeup $\mathrm{D}_{2} \mathrm{O}$ inventory for $\mathrm{D}_{2} \mathrm{O}$ losses. The operating $D_{2} \mathrm{O}$ inventory is the holdup in the fluid systems and storage tanks of the SSCR during operation of the plant. This inventory amounts to about 673,000 lbs. of $100 \% \mathrm{D}_{2} \mathrm{O}$, which is about $19 \%$ more than the cold $\mathrm{D}_{2} \mathrm{O}$ inventory of the reactor coolant system at the beginning of an equilibrium cycle $\left(566,000\right.$ lbs. of $\left.100 \% \mathrm{D}_{2} 0\right)$. A more detailed breakdown of the operating $\mathrm{D}_{2} \mathrm{O}$ inventory is shown in Table 3.1.9-1. 
The makeup $\mathrm{D}_{2} \mathrm{O}$ inventory serves to make up irrecoverable losses of $\mathrm{D}_{2} \mathrm{O}$ from the plant. This makeup needs to be maintained over the forty-year lifetime of the plant. The quantification of the makeup inventory is difficult because a portion of the $\mathrm{D}_{2} \mathrm{O}$ losses depends strongly on the operation of a particular plant and on the maintenance and service of the plant. The average annual makeup inventory is estimated as $1596 \mathrm{lb} /$ year of $100 \% \mathrm{D}_{2} 0$. Over forty years this amounts to about $63,800 \mathrm{lbs}$. of $100 \% \mathrm{D}_{2} 0$. The more detailed breakdown of the makeup inventory is shown in Table 3.1.9-1.

The sum of the operating and makeup $\mathrm{D}_{2} 0$ inventory during a forty-year plant life is 736,600 lbs. of $100 \% \mathrm{D}_{2} \mathrm{O}$. Thus, the SSCR needs an overall $\mathrm{D}_{2} \mathrm{O}$ inventory which is about $30 \%$ higher than the cold capacity of the reactor coolant system at the beginning of a cycle.

\section{1 .10}

$$
D_{2} O \text { LEAKAGE }
$$

The high cost of $\mathrm{D}_{2} \mathrm{O}$ and the radiological hazard due to airborne tritium from evaporated coolant make it mandatory to design the reactor coolant system more leak-tight than a conventional PWR. In general, leakage can be divided into two categories: recoverable and irrecoverable. Recoverable leakage leaves the coolant system boundary, is collected in a drain system and eventually upgraded and reused. With the exception of tritium activity release, this recoverable leakage is less of a problem for the SSCR than for a typical heavy water reactor (HWR). In a HWR this leakage must be 
TABLE 3.1.9-1

SSCR - STUDY

$\mathrm{D}_{2} \mathrm{O}$ INVENTORY

1. OPERATING INVENTORY

lbs. of $100 \% \mathrm{D}_{2} \mathrm{O}$

Reactor Coolant System

(at cold conditions)

566,300

Storage Tanks

64,100

$\mathrm{D}_{2} \mathrm{O}$ Upgrader

23,600

Auxiliary Systems Piping

18,800

Total

672,800

2. MAKEUP INVENTORY

lbs. of $100 \% \mathrm{D}_{2} \mathrm{O} / \mathrm{Year}$

Loss During Refueling

471

Irrecoverable Leakage from Fluid Systems

527

Coolant Sampling Losses

65

Changing of Ion Exchanger Resins

168

Degasifier Operation Loss

135

Upgrader Venting Loss

80

Reserve for Unforeseen Losses from Equipment 150

Total

1,596 
made up with highly concentrated reactor grade $D_{2} 0$. For the SSCR, this leakage constitutes a portion of the normal coolant system bleed for $\mathrm{D}_{2} \mathrm{O}$ concentration reduction and is made up with light water. The irrecoverable leakage is lost from the plant, e.g., via liquid or gaseous discharge. Here also the SSCR is faced with less of a problem than a HWR. On the average, the $D_{2} \mathrm{O}$ concentration in the fluid systems of a SSCR is only about $20 \%$ of the $D_{2} \mathrm{O}$ concentration of a HWR. Thus, equal liquid volumes of irrecoverable leakage are less expensive and less of a radiological hazard for the SSCR than for the HWR.

With the exception of the primary coolant system, most other $\mathrm{D}_{2} \mathrm{O}$-containing fluid systems operate at low pressure (up to about 150 psi) and temperature (less than $212^{\circ} \mathrm{F}$ ). This, in general, facilitates the task of making the SSCR system more leak-tight. Canned rotor pumps of existing design will be used for the smaller centrifugal pumps. For valves, available zero-leak designs (diaphragm valves) or conventional double valve stem packings with leak-off collection will be employed. In the piping network, welded connections will be used where possible or seal welds on flanges which cannot be eliminated.

It is difficult to estimate the amount of leakage under actual operating conditions. Assuming a leak-tight system design as described above, a total leakage of 1 iquid (recoverable and irrecoverable) of about 25 gallons/ day of 1 iquid appears feasible. This leakage rate is about $10 \%$ of the rate used for sizing leakage collection equipment for a conventional PWR. It is also in the same range as experienced during actual plant operation at the 
Argentinian $340 \mathrm{MW}(\mathrm{e})$ pressurized heavy water reactor at Atucha (about 10 gallons/day total leakage).

Most of this leakage of 25 gallons/day is recovered and only less than about 3 gallons/day of liquid is estimated to be lost irrecoverably in the SSCR. This amount is comparable to the operational values observed at Atucha (about $1 \mathrm{gallon} / \mathrm{day}$ ). The $\mathrm{D}_{2} 0$ loss associated with the 3 gallons/ day irrecoverable leakage is estimated as $1596 \mathrm{lb} /$ year of $100 \% \mathrm{D}_{2} \mathrm{O}$. The contributing sources for the $\mathrm{D}_{2} \mathrm{O}$ loss are described in more detail in Section 5.1.9.

\subsubsection{LOAD CHANGE CAPABILITY}

A short investigation was performed to compare the load change capability of the SSCR with that of the System 80 reactor. Effecting load changes in the SSCR by variation of the coolant $D_{2} 0$ concentration is impractical because a large excess $D_{2} \mathrm{O}$ inventory and a prohibitively large $\mathrm{D}_{2} \mathrm{O}$ upgrader facility would be needed. Variation of the coolant boron concentration as in the conventional PWR is also impractical, because the SSCR requires no boron for base-load operation and huge water volumes would be created during the deboration phase of a load change which subsequently would need to be processed by the boron evaporators. Thus, the study was performed using movement of the regulating control rods and transient variation of the average coolant temperature as the means of effecting load changes. The load change capability was evaluated for rapid transients (steps, ramps, load rejections), daily load cycles (100\% power - $50 \%$ power - $100 \%$ power) and return-to-power events (after a period of time at zero power). 
The results of the study show that the SSCR has comparable load change capabilities to the System 80 reactor for rapid transients and daily load cycling. In the return-to-power events, the SSCR can return to power less quickly than the System 80 because the excess reactivity to override xenon buildup which can be made available in the SSCR (primarily via lowering of the coolant temperature) is less than in System 80 (by lowering of the coolant temperature and temporary deboration).

Since this study showed that for the SSCR extensive use of the regulating control rods is needed to obtain load change capability comparable to the System 80 PWR, the SSCR requires fuel which is highly resistant to pelletcladding interaction (PCI). Also, a more detailed evaluation of the impact of significant short or long-term control-rod insertion near full power on local power generation and, subsequently, core thermal margins is required. 
The use of spectral shift control eliminates a substantial portion of the neutron inefficiencies of poison-control reactors. Excess neutrons which would otherwise be absorbed in control poisons are instead preferentially captured in the fertile component of the fuel. The productive utilization of these excess neutrons results in fuel makeup requirements which are lower than those of the conventional PWR, since more fissile material is produced and subsequently burned in the SSCR during operation than in its poison-controlled counterpart.

Incorporation of the more fuel-efficient spectral shift concept into the pressurized water reactor design is not without additional cost, however. These additional costs fall into two categories: those associated with the heavy water inventory, and those associated with the plant modification to control the concentration of heavy water and to process the diluted heavywater/light-water mixture prior to the next operating cycle. The savings in fuel costs which are obtained from the more efficient use of fuel resources are therefore largely mitigated by the additional cost required to realize the spectral shift concept.

\subsubsection{RESOURCE REQUIREMENTS}

Four fuel cycles were analyzed during the present evaluation of the SSCR. These fuel cycles were: 
a. $\mathrm{UO}_{2}$ once-through cycle with permanent disposal of spent fuel,

b. Denatured $\mathrm{U}-235 / \mathrm{ThO}_{2}$ cycle with recycle of recovered uranium and sale or storage of bred plutonium,

c. Denatured $\mathrm{U}-233 / \mathrm{ThO}_{2}$ cycle with recycle of recovered uranium and sale or storage of bred plutonium, and

d. Plutonium $/ \mathrm{ThO}_{2}$ burner reactor with the recycle of plutonium and sale of $\mathrm{U}-233$.

The first two of these fuel cycles use $\mathrm{U}-235$ as the initial and makeup fissile material, while the last two use special fuel materials (i.e., U-233 and plutonium), which must be supplied from an exogenous source. The resource requirements of the $\mathrm{U}-235$ fueled cycles can be measured in terms of their uranium ore and separative work requirements. The resource requirements of the cycles utilizing special fuel materials, however, can only be measured in terms of their consumption of these materials and/or their production of other fissile materials.

As part of the evaluation of the spectral shift concept, core optimization studies were conducted on the $\mathrm{UO}_{2}$ once-through fuel cycle and on the denatured $\mathrm{U}-235 / \mathrm{ThO}_{2}$ fuel cycle. The objective of these optimization studies was to identify possible core design changes (from the conventional PWR configuration) and/or fuel management strategies which result in improved resource utilization (primarily $\mathrm{U}_{3} \mathrm{O}_{8}$ requirements) and lower power generation costs for the SSCR. 
Based on the results of these core optimization studies, the core design was chosen identical to that of the reference Combustion Engineering, Inc. System 80 PWR. For the $\mathrm{UO}_{2}$ once-through fuel cycle, less than $8 \%$ improvement in $\mathrm{U}_{3} \mathrm{O}_{8}$ ore requirements and less than $1 \%$ reduction in fuel cycle cost can be achieved by modifying the lattice design, such as by reducing the fuel rod diameter or increasing the rod pitch. Furthermore, such modifications proved counter productive when recycle was considered. The use of high discharge exposure (about $50,000 \mathrm{MWd} / \mathrm{t}$ ) in conjunction with the relatively large number of in-core batches ( 5 versus 3 for present PWRs) however, results in a uranium savings of about $13 \%$ and lower fuel cycle costs (about $11 \%$ lower than any of the other cases analyzed). This fuelmanagement strategy has, therefore, been selected as representative of the optimized once-through cycle. Using the combination of higher burnup with an increased number on in-core batches allows annual refueling to be maintained and thus the same reactor availability as obtained with the present PWR refueling schedule. By allowing the fuel to remain in core longer and thus get more exposure before discharge, the fissile mater ia which is initially loaded and the fissile material bred during operation is more fully consumed. In addition, by utilizing five in-core batches, the core average exposure at end of cycle is reduced (compared to that of the three-batch scheme) thus decreasing the fission product burden on the fissile inventory. Of course, this same fuel management scheme is advantageous to the PWR; savings from this strategy similar to those of the SSCR are obtained as will be shown in the following discussion.

Since the current PWR lattice, to a large extent, has been designed with recycle in mind, the benefits of optimization of the SSCR are much more 
limited when recycle is employed, particularly when fuel cycle cost economics are considered. Those changes which improve fuel performance do so only slightly and, in general, with a substantial economic penalty. In particular, small uranium savings are obtained by reducing the fission product burden through the use of shorter refueling intervals and more incore batches (with a constant fuel discharge exposure). These fuel management strategies have an associate economic penalty, however, because of their adverse effect on reactor availability and/or because of their higher refabrication and reprocessing throughput.

For the denatured $\mathrm{U}-235 / \mathrm{ThO}_{2}$ cycle, little if any improvement in the fuel resource requirements can be achieved by modifying the lattice design. Typically, higher fissile inventories are associated with improvements in fuel performance of advanced converter reactors. For the denatured thorium cycle, those lattice variations which result in higher fissile inventories require higher loadings of uranium which are composed primarily of U-238 because of the restriction on the allowable enrichment of the uranium component. Since the additional uranium displaces thorium, more plutonium and less of the more desirable U-233 is bred. Thus, because of the decreased U-233 production, much of the potential gain derivable from lattice modification is not attained in the denatured thorium cycle. In addition, changes to the core design would probably delay the commercial introduction date of the SSCR substantially because of the need to develop engineering correlations and to qualify fuel of a different lattice geometry. Furthermore, the potential of backfitting spectral shift control into existing plants or plants under construction would be severely limited if modification to the core geometry were made. 
In view of the above considerations, it was felt that the SSCR core configuration should also be left unchanged from that of the reference PWR for the denatured $\mathrm{U}-235 / \mathrm{ThO}_{2}$ cycle. In addition, the conventional three-batch fuel-management scheme with annual refueling was retained. Although optimization studies were not performed for the denatured $\mathrm{U}-233 / \mathrm{ThO}_{2} \mathrm{cycle}$ or the plutonium $/ \mathrm{ThO}_{2}$ cycle, it was felt that the same general conclusions can be drawn as for the denatured $\mathrm{U}-235 / \mathrm{ThO}_{2}$ cycle. Of course, if an objective other than good overall fuel resource utilization is imposed, then these conclusions may not prevail. For example, it may be desirable to increase the production of $\mathrm{U}-233$ in the plutonium/ $/ \mathrm{ThO}_{2}$ cycle at the expense of higher plutorium consumption so that fewer transmutter reactors and more dispersed reactors can be deployed. This objective may be accompanied by poorer overall fuel utilization efficiency.

Uranium and separative work requirements of the $\mathrm{UO}_{2}$ once-through SSCR and the denatured $\mathrm{U}-235 / \mathrm{ThO}_{2}$ SSCR are shown in Table 3.2.1-1 together with those of the conventional PWR. For the $\mathrm{UO}_{2}$ once-through cycle, both a standard and an improved cycle are shown. The standard cycle corresponds to the conventional three-batch $30,000 \mathrm{MWd} / \mathrm{t}$ fuel-management scheme presently employed in PWRs. The improved cycle uses the five-batch high discharge fuel exposure fuel-management scheme selected in the core optimization studies for the SSCR. The $\mathrm{U}_{3} \mathrm{O}_{8}$ requirements of the SSCR are significantly below those of the PWR because of its improved neutron economy. Although the end of cycle fissile inventory in the two concepts is essentially the same, the higher conversion ratio during the cycle reduces the annual makeup requirements for a given energy extraction. The 
TABLE 3.2.1-1

\section{ESTIMATED FUEL RESOURCE REQUIREMENTS FOR PWR AND SSCR}

(30-Year Cumulative) ${ }^{1}$

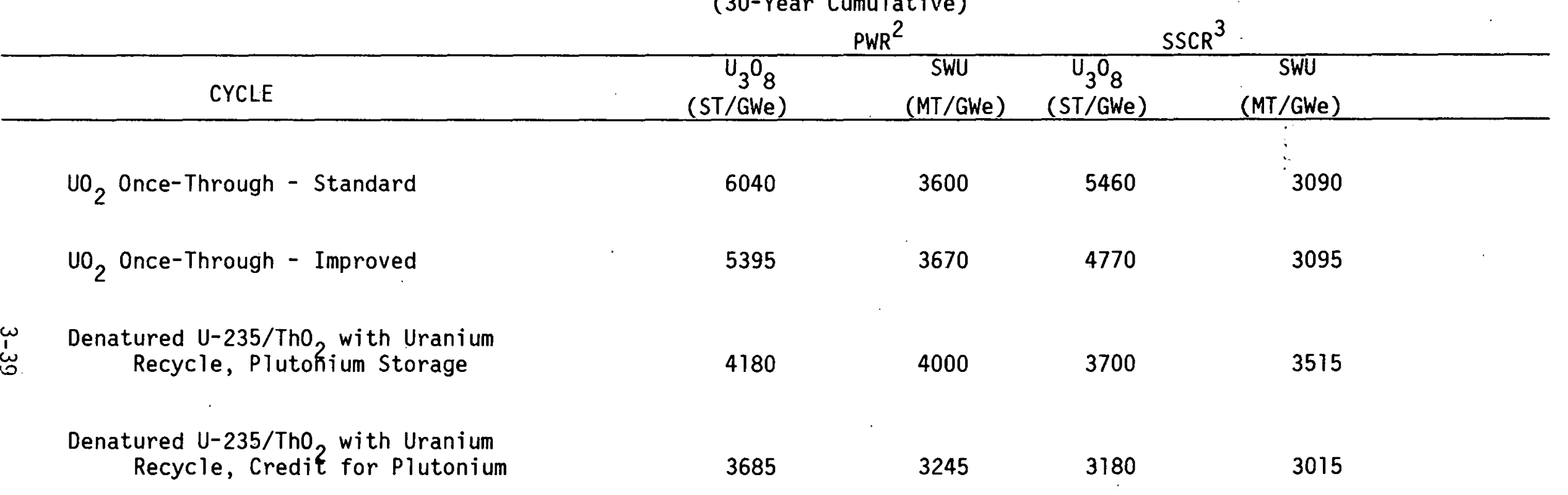

1. Based on $75 \%$ Capacity Factor and 0.2 wt\% Tails Assay; no credit for end of reactor 1 ife inventories

2. 1270 MWe PWR

3. 1260 MWe SSCR; 10 MWe Required for RCPs and $\mathrm{D}_{2} \mathrm{O}$ Upgrader 
savings in 30-year $\mathrm{U}_{3} \mathrm{O}_{8}$ requirements attributable to spectral shift control are about $11 \%$ for the $\mathrm{UO}_{2}$ once-through cycle (for both standard and improved fue 1 management schemes) and between 11 and 14\% for the denatured thorium cycle, depending on whether plutonium is stored or utilized. Similar savings in separative work are also obtained by the use of spectral shift control.

For the two fuel cycles requiring special fuel materials, the fuel utilization efficiency can be inferred from the data given in Table 3.2.1-2. In this table, a comparison is made between the PWR and the SSCR of the production and consumption of the two special fuel materials. For the denatured $\mathrm{U}-233 / \mathrm{ThO}_{2}$ cycle, the SSCR consumes $17 \%$ less $\mathrm{U}-233$ over the plant lifetime than the PWR, while at the same time producing about $16 \%$ more fissile plutonium. The spectral shift controlled reactor has an obvious advantage over the PWR for deployment at dispersed sites because of its lower U-233 requirement. For a given source of U-233 (e.g., from a thorium-blanketed fast breeder reactor), about $17 \%$ greater electrical capacity can be installed outside the secure production facility. In addition, $16 \%$ more plutonium in the form of spent fuel would be returned to the production facility for transmutation into $U-233$.

The complementary cycle to the denatured $\mathrm{U}-233 / \mathrm{ThO}_{2}$ cycle is the plutonium/ $\mathrm{ThO}_{2}$ cycle. In this latter cycle, plutonium bred in the former cycle (or any cycle which produces appreciable quantities of plutonium) can be converted (transmuted) into U-233 while generating electrical power. The U-233 can be denatured by blending it with depleted uranium to a uranium fissile 
TABLE 3.2.1-2

ESTIMATED SPECIAL FUEL REQUIREMENTS FOR PWR AND SSCF (Metric Tons/GWe) ${ }^{1}$

$\mathrm{PWR}^{2} \quad \mathrm{SSCR}^{3}$

Denatured U-233/Thorium

30-year U-233 Required (Net)

8.97

1.94

7.40

30-year Plutonium Fissile Produced

2.25

Plutonium/Thorium Burner

30-year Plutonium Fissile Required (Net)

30-year U-233 Produced.

22.18

8.07

21.99

$\stackrel{\omega}{1}$

1. Based on 75\% Capacity Factor; material losses included

2. 1270 MWe PWR

3. 1260 MWe SSCR; 10 MWe Required for RCPs and $D_{2} 0$ Upgrader 
content less than some prescribed limit (e.g., 12 wt\% U-233). The SSCR has an advantage over the PWR in that more U-233 is produced per quantity of fissile plutonium consumed. In the PWR, 0.36 grams of U-233 are produced per gram of fissile plutonium consumed, while in the SSCR, 0.41 grams of U-233 are produced per gram of fissile plutonium consumed.

The higher fuel efficiency of the SSCR operating on the denatured U-233/Th0 2 and the plutonium/ThO ${ }_{2}$ cycles makes it a more appealing candidate than the PWR for deployment in a nuclear economy employing restricted recycle of bred fuels. For the SSCR, more reactors can be located at dispersed sites and less within the confines of secure sites while maintaining a balance on the transmutation of plutonium fuel to denatured $\mathrm{U}-233$ fuel.

\subsubsection{TOTAL POWER GENERATION COST}

To obtain total power costs for the SSCR, it is necessary to determine the capital cost, the operation and maintenance (0\&M) cost, and the fuel cycle cost of a reactor employing spectral shift control. The capital cost estimates for a large spectral shift controlled reactor are based on the cost development by United Engineers and Constructors, Inc. (NUREG-0241) ${ }^{3}$ for a conventional PWR plus those additional costs needed to realize spectral shift control. The NUREG-0241 costs were escalated to January 1978 and then scaled with a 0.7 scaling factor to a PWR of $1270 \mathrm{MW}(\mathrm{e})$ (the reference PWR plant size). A total of $\$ 26$ million was added to the reactor plant equipment cost to account for the cost of modifying the PWR plant for 
spectral shift control (about $\$ 16 \mathrm{million}$ ) and to construct the $\mathrm{D}_{2} \mathrm{O}$ upgrader (about $\$ 10 \mathrm{million}$ ). The net electrical output of the SSCR is estimated to be about $1260 \mathrm{MW}(\mathrm{e})$. The $10 \mathrm{MW}(\mathrm{e})$ reduction in plant output compared to the reference PWR is a result of the additional pumping power needed to circulate the higher density coolant of the SSCR and the low pressure steam and electrical utilities to run the $\mathrm{D}_{2} \mathrm{O}$ upgrader. The resulting total unit capital costs is $\$ 599 \mathrm{KW}(\mathrm{e})$, excluding interest during construction, escalation during construction, and contingency allowance.

In order to establish power costs, interest during construction must be added to the base capital cost. This indirect cost will vary depending on the length of time required for construction, the schedule of payments during this period, and the cost of money (interest). Using a 10-year total construction period, a schedule of payments from Ref. 4 , and a $4.5 \%$ cost of money (deflated effective interest: rate) results in an interest during construction cost of $19 \%$ of the base capital cost, or a total capital cost of $\$ 715 \mathrm{KW}(\mathrm{e})$ in January 1978 dollars. This capital cost estimate does not include the cost of heavy water; the initial heavy water costs have been included with the fuel cycle costs for direct comparison with other advanced converters (e.g., the heavy water reactor).

Independent estimates of the operation and maintenance (0\&M) costs have not been made; however, it seems reasonable to base these costs on current pressurized water reactor $0 \& M$ costs plus some additional cost to account for $\mathrm{D}_{2} \mathrm{O}$ losses and maintenance on systems with potentially higher radiological 
hazard due to the presence of tritium. It is estimated that the additional costs to account for $\mathrm{D}_{2} \mathrm{O}$ losses from irrecoverable leakage during both refueling and operating cycles are small. However, the higher release of tritium wịll cause increased maintenance complexity, resulting in an 0\&M cost for the SSCR of about $1.85 \mathrm{mi} 11 \mathrm{~s} / \mathrm{kWh}$ (approximately $0.1 \mathrm{mills} / \mathrm{kWh}$ higher than that of the PWR).

The fuel cycle costs calculated for the SSCR are based on 30-year levelized costs and the economic assumptions of Ref. 5. These economic assumptions, which are given in Table 3.2.2-1, have been used widely by the U.S. Department of Energy in their recent nuclear systems evaluation programs and have been selected for use by the Nonproliferation Alternative Systems Assessment Program contractors to form a common economic basis by which the fuel cycle costs of the various reactor concepts can be intercompared. The heavy water inventory cost, which is included in the fuel cycle cost of the SSCR, is based on a 60 wt\% heavy water concentration and a heavy water cost of $\$ 80 / 7 \mathrm{~b} \mathrm{D}_{2} \mathrm{O}$. This unit cost is about $18 \%$ below recently published costs for reactor grade heavy water. Since the SSCR does not use heavy water of this high purity $\left(99.97 \mathrm{wt} \% \mathrm{D}_{2} 0\right)$, presumably there would be a cost savings resulting from the elimination of some of the final stages from the heavy water production facility. Based on these assumptions, the heavy water inventory cost is about $\$ 54$ million, which represents a contribution to the fuel cycle cost of $0.65 \mathrm{mi} 11 \mathrm{~s} / \mathrm{kWh}$ when a $10 \%$ fixed charge rate is used.

The fuel cycle costs and total power costs for the SSCR are shown in Table 3.2.2-2 along with those of the $\mathrm{UO}_{2}$-fueled PWR for reference. The improved cycles employ the five-batch, extended exposure fuel management scheme, 
TABLE 3.2.2-1

ECONOMIC AND RESOURCE PARAMETERS

Near Term ${ }^{a} \quad$ Long Term ${ }^{b}$

Net Power Rating, MW(e)

SSCR

1260

PWR

1270

Nominal Capacity Factor, \%

$\mathrm{U}_{3} \mathrm{O}_{8}$ Costs, $\$ / 1 \mathrm{~b}$

40

100

Thorium, $\$ / 1 \mathrm{~b}$

15

Conversion, $\$ / \mathrm{kg}$

4

Separative Work, $\$ / \mathrm{kg}$ SWU

100

Fabrication Costs, $\$ / \mathrm{kg} \quad H M$

LE U5-U8

106

DE U5-U8

139

123

DE U3-U8

664

574

Pu-Th

438

379

$\mathrm{ThO}_{2}$ Reprocessing Costs, $\$ / \mathrm{kg} H \mathrm{HM}$

241

154

Shipping and Waste Storage, $\$ / \mathrm{kg} H M$

85 Throwaway

Cost, $\$ / \mathrm{kg} \quad H M$

150

$\mathrm{D}_{2} \mathrm{O}$ Price, $\$ / 7 \mathrm{~b}$.

80

Enrichment Tails Assay, wt\%

0.2

Reactor Plant Life, years

30

Discount Rate, \%

4.525

Fixed Charge Rate, \%

10

Carrying Charge Rate, \%

8

assumes a developed industry

${ }^{b}$ Assumes high capacity industry 
TABLE 3.2.2-2

$\frac{\text { TOTAL POWER COSTS }}{(\text { Mills } / \mathrm{kWh})}$

Cycle

U02 Cycles

Standard PWR

Improved PWR

Standard SSCR

Improved SSCR

Th02 Cycles

Denatured U-235 SSCR

Denatured U-233 SSCR

U-233 Value: $\$ 10 / \mathrm{gm}$

$\$ 30 / \mathrm{gm}$

Plutonium SSCR

U-233 Value: $\$ 10 / \mathrm{gm}$ $\$ 30 / \mathrm{gm}$

Capital Costs

10.50

10.50

10.88

10.88

10.88

10.88

10.88

1.76

1.76

1.85

1.85
Fuel Cycle Costs ${ }^{1,2}$

$6.20(10.59)$

$5.54(9.50)$

$6.20(10.12)$

$5.54(9.04)$

1.85

$8.50(10.96)$

fiss

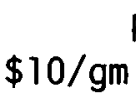

1.85

$5.54(4.85) \quad 5.36(4.67)$

$7.09(6.40) \quad 6.91(6.22)$

1.85

$5.09(4.55) \quad 8.52(7.97)$

$4.35(3.80) \quad 7.77(7.22)$
Power Costs ${ }^{2}$

$18.46(22.85)$

$17.80(21.76)$

$18.94(22.85)$

$18.27(21.77)$

$21.23(23.69)$

$\underset{\$ 10 / \mathrm{gm}}{\text { Pu fiss }} \stackrel{\text { Value }}{\$ 30 / \mathrm{gm}}$

$18.27(17.58) \quad 18.09(17.40)$

$19.82(19.13) \quad 19.64(18.95)$

$17.82(17.28) \quad 21.25(20.70)$

$17.08(16.53) \quad 20.50(19.95)$

Notes: 1. Heavy Water Inventory Cost of $0.65 \mathrm{mill} / \mathrm{s} / \mathrm{kWh}$ included

2. Near-Term Cost Assumptions (Long-Term Cost Assumptions) 
while the standard cycles employ the conventional three-batch PWR fuel management scheme. It can be seen from the data presented in this table that the $\mathrm{UO}_{2}$ once-through SSCR is competitive with the PWR for uranium prices of about $\$ 100 / 1 \mathrm{~b}$. At lower uranium prices, the costs of modifying the PWR for spectral shift control and the heavy water inventory costs more than balance the savings in fuel costs. As the uranium costs become a larger fraction of the total fuel cycle costs, the better resource utilization using spectral shift control results in a cost savings for the SSCR.

The denatured $\mathrm{U}-235 / \mathrm{ThO}_{2} \mathrm{SSCR}$ is not competitive with the $\mathrm{UO}_{2}$-fueled $\mathrm{SSCR}$, even in the long term when the price of uranium reaches $\$ 100 / 1 \mathrm{~b}$ and the recycle process unit costs (e.g., for refabrication and reprocessing) decrease. Even in the long term; the high cost of fabricating the gammaactivated recycle fuel and the high fissile inventory. charges (accrued in the early cycles before recycle begins) cause the fuel cycle costs of this cycle to exceed those of the uranium cycle. As the price of uranium increases beyond $\$ 100 / 1 \mathrm{~b}$, the fuel cycle costs and consequently the power costs become more competitive with those of the uranium cycle.

The fuel cycle costs and total power costs for denatured U-233/ThO $\mathrm{SSCR}_{2}$ and the plutonium/ThO ${ }_{2}$ SSCR are shown as functions of both the $U-233$ value and the fissile plutonium value. The actual value of these two special fuel materials can be assessed only when total nuclear power system economics are considered; proper account must be made of the supply and demand for these materials before realistic values can be assigned. Intercomparisons 
of the costs of these fuel cycles with U-235 fueled cycles is, therefore, difficult without a systems analysis. However, since the fuel cycle costs are linear in both $\mathrm{U}-233$ value and $\mathrm{Pu}$ fissile value, once the values of these two fissile materials are known, correct fuel cycle costs can be obtained from the data in Table 3.2.2-2. 
Since the spectral shift controlled reactor is basically a modified PWR, the fuel management aspects of the two reactor types are quite similar. The dominant factor which influences the fuel management characteristics of these reactors is their use of partial batch refueling. The reactor core for both concepts is housed in a pressure vessel which is sealed during normal operation but which is periodically opened for replacement of spent fuel. The discrete nature of this refueling operation, together with the required time and economics of the operation, dictate that part of the core should be replaced at infrequent intervals. Because of annual load variations, utilities have traditionally refueled their reactors each year during one of the lowdemand periods. At these times, about one-third of the fuel assemblies, those with the highest fuel exposure, are replaced. This refueling batch size was selected as a compromise between ease of fuel management and economics.

\section{3 .1}

DIFFERENCES BETWEEN FUEL MANAGEMENT IN THE SSCR AND IN THE PWR

In the conventional PWR, reactivity control is achieved through the introduction of soluble boron into the reactor coolant to capture the excess neutrons generated throughout plant life. The soluble boron concentration is relatively high at beginning of cycle and is gradually reduced during the operating cycle by the introduction of pure light water. In the SSCR, 
excess reactivity control is achieved by the addition of heavy water to the reactor coolant. Because of the poorer moderating properties of heavy water, the neutron spectrum is shifted to higher energies where the neutrons are preferentially absorbed in the fertile material. During the operating cycle, the heavy water content of the coolant is decreased by dilution with light water as in the conventional PWR to compensate for fuel depletion.

The heavy water concentration required to control the excess reactivity of the core is dependent on the fuel type loaded, the cycle being considered, and the fuel management strategy employed. In general, the heavy water concentration at beginning of cycle of the initial core is 50-60 wt\% (after equilibrium xenon builds in) and decreases nearly linearly to about 2 wt\% at the end of cycle. This beginning-of-cycle concentration is sufficient to control all the excess reactivity of the core and can be raised only by increasing the fuel loading or changing the lattice geometry (e.g., increasing the water-to-fuel ratio). The $2 \mathrm{wt}$ end-of-cycle heavy water concentration was selected as a practical lower limit which can be economically attained. Very little additional reactivity is tied up in this last $2 \mathrm{wt} \%$ heavy water. In addition, the sizing requirements and therefore the cost of the $\mathrm{D}_{2} \mathrm{O}$ upgrader become prohibitive as the concentration becomes. lower. After the initial cycle, because of the buildup of fission products and other parasitic isotopes, the beginning-of-cycle concentration is substantially less than that of the initial cycle, ranging from 38 wt\% for the $\mathrm{UO}_{2}$ once-through cycle to $54 \mathrm{wt} \%$ for the denatured $\mathrm{U}-233 / \mathrm{ThO}_{2}$ cycle two.

The high soluble boron concentration at the beginning of cycle in a PWR, particularly for the first cycle, can result in a very small or even 
positive moderator temperature coefficient (MTC). Traditionally, burnable poison shim rods have been used to reduce the soluble boron requirements and thus assure an acceptable MTC. Since large concentrations of soluble boron are not utilized in the SSCR, the need for poison shim rods has been eliminated and consequently fuel management has been simplified. The auxiliary function of the shim rods, that of helping attain acceptable radial power distributions, is achieved by judicious use of additional fuel enrichments (no more than one or two).

Neutron leakage from a large current design PWR is about 4\%, with a radial leakage constituting 2.5 to $3.0 \%$ and the axial leakage the remainder. Throughout the operating cycle, the leakage is relatively constant, displaying only a slight increase as the power of the peripheral assemblies increases with core exposure. The neutron leakage from a large SSCR is greater than that of the PWR by 15 to $20 \%$ at beginning of cycle because of the longer diffusion lengths in the heavy water moderated core. As the core depletes and the heavy water concentration is reduced, the neutron leakage decreases, becoming comparable to that of the PWR at end of cycle. From the standpoint of total neutron economy, this higher leakage is not particularly significant since averaged over the cycle it represents only about an additional $0.3 \%$ loss of neutrons, which is a small fraction of the gain resulting from the improved neutron efficiency of spectral shift control.

Another consequence of the longer diffusion lengths in the SSCR is that the core is less sensitive to local variations in reactivity at the beginning 
of cycle. Power peaking in adjacent assemblies as a result of mismatches in fuel reactivity are less pronounced than in the PWR. Fresh fuel of higher reactivity (enrichment) can be loaded in the SSCR than in the PWR and still achieve acceptable core power distributions. This makes less traditional fuel management schemes, such as the use of 18-month refueling or the five-batch/high-burnup strategy more easily achievable. As the core depletes and the diffusion length decreases, the reactivity of the high reactivity/high power assemblies also decreases due to depletion, so that power peaking problems do not develop late in the cycle when the core looks similar to that of the PWR.

\section{3 .2 \\ $\mathrm{UO}_{2}$ ONCE-THROUGH SSCR CORE}

The SSCR core optimization study indicated that substantial savings in both resource utilization and fuel cycle cost can be achieved by use of a fivebatch extended burnup fuel-management scheme for the $\mathrm{UO}_{2}$ once-through cycle. As the burnup is increased, the resource utilization improves because of the increased in situ utịlization of plutonium and the more complete consumption of $U-235$. Hence, the quantity of fissile material unproductively residing in spent fuel is decreased. The use of a larger number of in-core batches improves resource utilization by reducing the core average burnup and thus the fission-product burden at the end of cycle. This allows the fuel to operate to higher discharge exposure before refueling is required. 
To implement this fuel-management strategy, $20 \%$ of the core is replaced each year (compared to $33 \%$ as presently practiced in the conventional PWR). The length of each operating cycle is still maintained at about one year, with the fuel resident in-core five years versus three years for current PWR fuel management. To maintain annual refueling while loading only $60 \%$ of the fuel previously loaded, requires that the fuel enrichment be substantially higher than that previously employed. Fortunately, the entire reload batch can be accomodated on the core periphery where the assembly power is typically low because of neutron leakage.

There are two effects which partially reduce the potential gain from this improved fuel-management scheme: increased core leakage and higher than anticipated core average exposure at end of cycle. With the higher feed enrichment, the reactivity of the fresh fuel located on the core periphery is increased. This higher reactivity leads to higher neutron leakage (about 10\% higher than the equivalent three-batch SSCR). Also, in the five-batch fuel management scheme, fuel accumulates relatively more burnup in the earlier cycles of its residency than does fuel in the three-batch scheme. For a given discharge exposure, this leads to a higher core average exposure at end of cycle. A combined enrichment penalty for the equilibrium cycle on the order of 0.15 wt\% results from these two effects, partially reducing the potential uranium utilization improvement associated with the five-batch fuel management scheme.

\subsection{3 $\mathrm{ThO}_{2}$ SSCR CORES}

The three thorium-based fuel cycles have fuel management characteristics which are quite distinct from one another. The denatured U-235/ ThO ${ }_{2}$ cycle 
is initially fueled with 20 wt\% uranium in thorium. The annual makeup fuel consists of two components: a fresh 20 wt\% uranium component and a 93 wt\% uranium "topping" component. Since the conversion ratio is less than unity in the SSCR, the fissile enrichment of the uranium recovered in the denatured $\mathrm{U}-235 /$ thorium fuel cycle is less than that loaded. In the $\mathrm{UO}_{2}$ fuel cycle, it has been envisioned (assuming recycle would be allowed) that recovered uranium would be returned to the enriching plant for reenrichment. This would not be done with U-233 bearing fuels because of their high radioactivity which results from $\mathrm{U}-232$ contamination. Thus the need for a reenrichment strategy, in the form of a "topping" material, arises for denatured fuel. The topping component is mixed with recycle uranium to bring the enrichment of this uranium mixture to the maximum allowable fissile content. This strategy maintains the U-238 content of the denatured fuel as small as possible, which allows the maximum amount of U-233 and the minimum amount of plutonium to be bred. The $20 \mathrm{wt} \%$ component is the makeup fuel material that fills the remainder of the batch. The two fuel components are kept segregated from one another because the recycle fuel is highly radioactive (as a result of U-232 contamination) while the $20 \mathrm{wt} \%$ makeup fuel is not. This strategy results in a very large fraction. of the fuel being radioactive, which imposes an economic penalty. (in the form of higher fabrication costs). It does, however, produce the largest quanitity of denatured fuel exportable to dispersed (unsecured) reactor sites. The plutonium bred from the denaturant $(U-238)$ is either stored for future use or burned in a secure nuclear energy center (NEC).

The denatured $\mathrm{U}-233 / \mathrm{ThO}_{2}$ cycle is fueled entirely with $\mathrm{U}-233$ (denatured with depeleted uranium) from an exogenous source. As such, every fuel assembly is radioactive, requiring remote fabrication and special handling 
of fresh fuel. The in-core fuel management, however, is less complicated than that of the denatured $\mathrm{U}-235 \mathrm{ThO}_{2} / \mathrm{cycle}$, since every assembly in the batch is composed of the same material. In addition, because of the high initial reactivity of $U-233$ bearing fuel, this fuel cycle requires the highest beginning of cycle $\mathrm{D}_{2} \mathrm{O}$ concentration of any of the thorium-based fuel cycles. Since the recycle and makeup fuel are identical and since the higher uranium isotopes (higher than U-233) are slow to build up because of the low capture cross section of $U-233$, near equilibrium conditions are established in only a few cycles. This fact makes the cycle-by-cycle fuel management considerably easier since, once equilibrium has set in, the same fuel shuffling pattern applies to all subsequent cycles. Approximately $50 \%$ more plutonium is produced in this cycle than in the denatured $\mathrm{U}-235 /$ $\mathrm{ThO}_{2}$ cycle because of the lower allowable enrichment of $\mathrm{U}-233$ bearing fuel ( 12 wt\% vs. 20 wt\% for U-235 bearing fue 1).

The plutonium/ $/ \mathrm{ThO}_{2}$ cycle is viewed as a transmutter.cycle which takes plutonium generated in a uranium-based fuel cycle or a denatured thorium cycle and converts it into U-233. The chemically separable uranium component contained in the spent fuel from this reactor is almost pure fissile material (greater than $92 \mathrm{wt} \%$ ) and as such must be safeguarded. Since this fuel cycle accepts a weapons-usable material--plutonium, and converts it into another weapons-usable material--U-233, it can be deployed only with a secure NEC. However, the recovered uranium can be easily denatured by mixing it with depleted uranium within the security of the NEC and then used to fuel reactors outside the NEC. 
As with the denatured $\mathrm{U}-233 / \mathrm{ThO}_{2}$ cycle, every assembly in a plutonium/ $/ \mathrm{ThO}_{2}$ batch is composed of the same fuel material since all plutonium-bearing fuel is radioactive and therefore requires some type of remote or semiremote fabrication technique. Again, near equilibrium conditions are quickly attained once the initial core fuel (low burnup fuel) is discharged. Power mismatches between adjacent assemblies are not a problem as they can be in cores where only some of the assemblies are plutonium-fueled. Therefore, the familiar problem of requiring enrichment zoning in the mixed-oxide assemblies of a self-generated $\mathrm{UO}_{2}$ recycle core does not exist in this core.

One fuel-management characteristic that is similar in all three thoriumbased cycles is the cycle energy distribution for the initial cycles. Because of the low initial reactivity of thorium-based fuels, high loadings would be required to achieve the long first cycle typical of $\mathrm{UO}_{2}$-fueled cores. Moreover, with these high initial core loadings, the second cycle would be considerably longer than that for the comparable $\mathrm{UO}_{2}$ core because of the shallow slope of the reactivity depletion curve: Therefore, a more attractive alternative is to employ a shorter first cycle, so that the total energy produced in the initial three cycles is comparable to that of the $\mathrm{UO}_{2}$-fueled core.

For all of the thorium cores, equal cycle exposures were selected for the first three cycles, the value selected being equal to the equilibrium $75 \%$ capacity factor exposure. This can be contrasted to a typical $\mathrm{UO}_{2}$ fuel cycle which has a long first cycle (e.g., 16\% longer than the equilibrium) followed by a short second cycle (e.g., $16 \%$ shorter than the equilibrium). 
An evaluation of the safety and licensing aspects of the SSCR was performed. The evaluation of the SSCR with respect to postulated accidents was primarily qualitative in nature and relied heavily on comparisons with the System $80^{\text {TM }}$ PWR.

\section{4 .1} SAFETY-RELATED PLANT PARAMETERS

The SSCR is basically a PWR and, especially at the end of a cycle, the core parameters which are of significance for accident analyses are very much similar to the ones of a PWR, since in both cases the coolant is composed essentially of light water. However, some of these core parameters are different at the beginning of a cycle when the presence of $\mathrm{D}_{2} \mathrm{O}$ and the absence of boron in the coolant cause the greatest difference to a PWR. The moderator temperature coefficient is substantially more negative in the SSCR at the beginning of a cycle than in the PWR, e.g., about $-5 \times 10^{-2}$ $\% \Delta \rho /{ }^{\circ} \mathrm{F}$ for the SSCR and about $-i \times 10^{-2} \% \Delta \rho /{ }^{\circ} \mathrm{F}$ for the PWR. Also, the Doppler coefficient at the beginning of a cycle is different. It is greater than for a PWR because of the larger fractional neutron absorption in the fertile material. Due to the rarder neutron spectrum resulting from the presence of $D_{2} \mathrm{O}$ in the coolant, a reduction of the effectiveness of the control rods might be anticipated. However, the thermal diffusion length is longer in $\mathrm{O}_{2} \mathrm{O}$ and the control rods are "seen" by neutrons from a greater istance. As a consequence of these competing effects, the control rod woin is comparabie to that of a PWR. 
The tritium production of a SSCR is considerably greater than in a PWR. This leads to a saturation tritium activity at the end of a forty-year plant life of $1100 \mu \mathrm{Ci} / \mathrm{CC} \mathrm{D}_{2} \mathrm{O}$. Depending on the $\mathrm{D}_{2} \mathrm{O}$ contentration of the $\mathrm{D}_{2} \mathrm{O} / \mathrm{H}_{2} \mathrm{O}$ coolant mixture, this results in a tritium activity in the coolant of a SSCR which is between twenty to several hundred times higher than in the PWR.

\subsubsection{ACCIDENT ANALYSES}

The evaluation of the accident response of the SSCR was done in the framework of the accident analyses which are performed in Section 15 of Combustion Engineering's Final Standard Safety Analysis Report, CESSAR (Ref. 1). A multitude of incidents which could initiate an accident are grouped into an event/frequency matrix which consists of the following eight event-type categories and five frequency-of-occurence categories:

Event Types:

1. Increase in heat removal by the secondary system.

2. Decrease in heat removal by the secondary system.

3. Decrease in reactor coolant system flow rate.

4. Reactivity and power distribution anomalies.

5. Increase in reactor coolant inventory.

6. Decrease in reactor coolant inventory.

7. Radioactive release from a subsystem or component.

8. Increase in primary system pressure. 
Frequency-of-Occurrence Types:

1. Moderate frequency incidents.

2. Infrequent incidents.

3. Not likely to occur during plant life.

4. Low probability of occurrence during plant life.

5. Exceedingly low probability of occurrence during plant life.

Acceptance criteria related to fuel performance, radiological release or primary system pressure are defined for each of the frequency-of-occurrence categories by which it is determined whether the consequence of an accident is acceptable or not. Based on the experience with the System $80^{\mathrm{TM}}$ accident analysis and based on an assessment of the effect of the difference of safety-related core parameters, eleven incidents were evaluated in more detail. These are incidents which either have the most severe consequences in a PWR or which might be influenced most strongly by the difference between SSCR and PWR. With the exception of the steam-line-break incident, all other incidents indicate consequences for a SSCR which are not materially different from a PWR. As might be expected from the more negative moderator temperature reactivity coefficent of the SSCR at the beginning of a cycle, the reactor coolant system temperature drop after a steam-line break causes a larger reactivity increase in the core than for a PWR. This, in turn, results in a return to power for the SSCR even after insertion of the control rods, while the System 80 reactor avoids return to power. Return to power in the SSCR could be avoided also, by providing about $1.5 \% \Delta \rho$ additional control rod worth. The return-to-power in the 
SSCR is not considered a safety problem, because the return to power was predicted using conservative analysis models. It is expected that by using improved analysis methods, the requirement for an increase in shutdown worth for the SSCR can be avoided.

The loss-of-coolant accident is not expected to be more severe than for the PWR, even for high burnup fuel with higher fuel rod internal gas pressure. Bursting of the cladding would occur earlier in the blowdown phase than in a PWR. However, this separates the cladding from the fuel and causes it to be cooled down more during the rest of the blowdown phase. Thus, the maximum cladding temperature which occurs about a minute latei during the reflood phase is not expected to be higher than for the PWR.

The contribution of the coolant tritium activity to the site boundary dose after an accident turned out to be a small fraction of the total dose. A steam generator tube rupture releases the largest mass of primary $c 00^{\urcorner-n t}$ to the atmosphere, resulting in a tritium activity of about $300 \mathrm{Ci}$. For this activity level, the tritium beta skin dose is about $8 \times 10^{-5}$ rem. This is a small fraction of the total dose resulting from the release of all the other radioactive isotopes in the primary coolant.

Inadvertent injection of unborated light water into the coolant system would cause an increase in reactivity when the $\mathrm{D}_{2} \mathrm{O}$ concentration is high. This accident is similar to unborated water addition in the PWR. With similar controls as in the PWR, the $\mathrm{D}_{2} \mathrm{O}$ dilution can be prevented in the SSCR or its consequences satisfactorily controlled. 
The longer mean path length of the neutrons in the $\mathrm{D}_{2} \mathrm{O}$-containing coolant of a SSCR causes a neutron fluence at the wall of the reactor vessel which is about $30 \%$ higher than for a PWR. The resulting increase of the nilductility transition temperature by about $20^{\circ} \mathrm{F}$ at the end of the vessel life appears to be tolerable.

\section{TRITIUM RELEASE DURING NORMAL OPERATION}

Tritium release and exposure to tritium during normal operation is minimized, in general, by designing leak-tight fluid systems as described in Section 3.10. Tritium release affects the accessibility of buildings containing $\mathrm{D}_{2} 0$-carrying equipment. Accessibility is determined by not exceeding the maximum permissible concentration (MPC) for tritium $\left(5 \times 10^{-6} \mu \mathrm{Ci} / \mathrm{cc}\right.$ air for unlimited access). Tritium in gaseous or liquid form is also the dominant contribution to the activity level of discharges to the environment.

During normal power operation, the containment building is isolated from the outside environment. Thus, $D_{2} 0$ leakage inside the containment building has no effect on the airborne release to the site boundary. If the leakage is less than about $12.5 \mathrm{lb} / \mathrm{day}$, the tritium concentration is below the MPC. It is estimated that with leak-tight fluid systems this low leak rate can be realized. The $\mathrm{D}_{2} \mathrm{O}$-containing equipment in the annulus and solid waste and decontamination building is arranged in self-contained isolated cubicles with separate air recirculation. Thus, any leakage within a cubicle has 
no effect on the airborne release to the site boundary. If the tritium concentration of a cubicle exceeds the MPC, it can be diluted sufficiently by injection of steam before access. In general, it is expected that due to the higher tritium level in the coolant, stricter precautions for maintenance and repair work than in a PWR will be required for the SSCR in order to limit occupational radiation exposure of plant personnel.

The magnitude of tritium release to the environment is essentially determined by the amount of leakage from primary to secondary system in the steam generators. Although the majority of PWR steam generators operate without detectable leakage, a leakage of about $30 \mathrm{lb}$ of liquid per day was assumed for the safety assessment of the SSCR. Under this assumption, the total activity released to the environment is about $1950 \mathrm{Ci} /$ year. About $620 \mathrm{Ci} /$ year are released in gaseous form while the remainder of about 1330 $\mathrm{Ci} /$ year is released in liquid form. The atmospheric release is less than the comparable value (about $760 \mathrm{Ci} /$ year) which would be used in the safety assessment of a conventional PWR. Thus, with respect to atmospheric discharge, siting of a SSCR should be no more difficult than for a PWR. The liquid release of the SSCR is about two times higher than the comparable safety assessment value of the PWR (760 Ci/year). The permissible liquid release rate depends very much on the geology and hydrology of a specific plant site. It is estimated that for the majority of plant sites, the liquid release of the SSCR would not exceed site limits. 


\section{4 .5

Based on the general similarity of the SSCR and a PWR, and on the preceding safety assessment, it does not appear that the SSCR is confronted by significant licensing issues which arise from spectral shift operation. It is anticipated that a SSCR could be licensed after a detailed design has been developed and a safety analysis has been submitted for review. 
The proof of principle of spectral shift operation was demonstrated by the Vulcain experiment in the BR-3 nuclear plant at Mol, Belgium. The BR-3 plant, after two years of operation as a conventional 11 MW(e) PWR, was modified for spectral shift control operation and successfully operated with this mode of control between 1966 and 1968. Subsequently, the BR-3 reactor was returned to conventional PWR operation.

The present SSCR study confirms the conclusions of the earlier work as to the close resemblance of the SSCR to a conventional PWR. The specific modifications for SSCR operation utilize components and design concepts which are in use either in the light water or heavy water reactor field and do not exceed state-of-the-art technology.

Deployment of SSCR plants will require some engineering development work, primarily for experimental verification. 6 igh on the list of development items is the experimental verification of the effectiveness of the coolant flushing exchange operation prior to refueling. The hydraulics of this process need to be studied and its overall effectiveriess in terms of necessary flush volume and final $D_{2} 0$ concentration of the rest volume need to be quantified. Flow tests of large-scale models of the reactor vessel and associated coolant piping will be required for this task. A test program of this type is estimated to cost bstaten $\$ 50,000$ and $\$ 250,000$, depending on model scale and extent of test program. 
Critical heat flux data for PWR fuel geometries and $\mathrm{D}_{2} \mathrm{O}$ concentrations typical of the SSCR are essentially nonexistent. These data are needed for detailed thermal-hydraulic design calculations and safety analyses. The first step in developing the data would be to determine whether critical heat flux correlations which were developed for light or heavy water can be corrected for use with heavy-water/light-water mixtures. It is expected that as a minimum, small-scale benchmark heat transfer tests are required for confirmation of applicability or for generation of correction factors. If this approach proves impractical, heat transfer tests might be necessary to develop specific correlations for heavy/light water mixtures. The cost of a test program is expected to range between $\$ 100,000$ and $\$ 250,000$, depending on whether benchmark tests or a complete test program is required.

Fuel-cycle-related R\&D consists of physics verification of analytical methods and safety-related parameters. This effort would help provide the data base required to support the licensing process. For $\mathrm{UO}_{2}$ fuel, this data base has been partially developed in the initial SSCR development work performed by the USAEC in the $1960 \mathrm{~s}^{6}$. However, additional work, primarily in the area which establishes reactivity predictions, power distribution, $\mathrm{D}_{2} \mathrm{O}$ worths, and control rod worths is still required for uranium fuel. No previous physics verification tias been performed for the denatured thorium fuels or for plutonium/thorium fuei. The cost of the R\&D effort could range from several million to well above ten million dollars, depending on the fue 1 systens to be investigated and on how much work from PWR improvement programs can be applied to the SSCR. 
Presently-available on-line instruments for $\mathrm{D}_{2} \mathrm{O}$ concentration measurement do not include the full range of concentrations occurring during spectral shift operation. Additional engineering effort of about $\$ 100,000$ is required to develop on-line concentration measurement units which cover the range of SSCR $\mathrm{D}_{2} \mathrm{O}$ concentrations ( $0.1 \mathrm{wt} \%$ to $85 \mathrm{wt} \%$ ) with good accuracy and which are reliable in operation.

If it becomes necessary to reduce the release of tritium to the environment, it is conceivable that the technology for separating tritium from $\mathrm{D}_{2} \mathrm{O}$ may need to be developed further. Distillation and electrolysis appear to be the most likely candidates for implementation of a commercial tritium upgrading . unit. Units are already available based on cryogenic distillation for use with heavy water reactors, where the problem of tritium production is somewhat more severe. The cost of an initial feasibility study encompassing process evaluation and selection as will as initial design development, may be desirable because of the difference in the quantity and concentration of the liauid volume to be processed. It is estimated that an initial feasibility study of this type would cost about $\$ 200,000$.

Use of high burnup fuel will require an extensive development program including in-pile irradiation. This fuel development, however, is not directly required for spectral shift control. Instead, it is a generic effort which is desirable for conventional poison control PWRs as well as spectral shift control PWRs to improve fuel utilization and power costs. The estimate for the cost of a fuel development program is on the order of $\$ 1,500,000$ for high burnup $\mathrm{UO}_{2}$ fuel and $\$ 2,500,000$ for thorium fuel. Because of the similarity of SSCR and LWR fuel, it can probably be assumed that the fuel development will be conducted under LWR R\&D programs. 
Apart from the LWBR, the spectral shift controlled reactor is unique among the advanced converter systems being considered in NASAP because it is founded on PWR technology and built of PWR components. This relationship with the PWR brings to the SSCR not only marked advantages, but some disadvantages as well. For example, the fuel resource requirements of the SSCR, although well below those of the conventional PWR, are not as low as achievable in some other alternatives, e.g., in the heavy water reactor (HWR). Both the basic nuclear properties of light water and the lack of on-line refueling limit the fuel utilization efficiency of the SSCR to below that of the HWR. On the other hand, the SSCR is essentially a current-design PWR to which is added a $\mathrm{D}_{2} \mathrm{O}$ upgrader. The major plant components, e.g., reactor vessel, steam generators, primary coolant system, and secondary steam plant are the same as in a PWR. They represent present technology for which manufacturing techniques and capacity already exist. Even the $\mathrm{D}_{2} \mathrm{O}$ upgrader is similar to designs already in operation at the Canadian HWR power stations. Depending on the worldwide availability of $\mathrm{D}_{2} \mathrm{O}$, one area that may require substantial expansion if the SSCR were to be commercially deployed on a large scale is in heavy water production capacity. A typical large SSCR requires an initial $D_{2} 0$ inventory of about 600,000 1bs. and an annual makeup of about $0.2 \%$ of this value to replace irrecoverable losses.

From a commercialization standpoint, the SSCR should probably be viewed as a major advancement in the evolution of the improved PWR. A number of 
modifications/operating strategies, which show considerably less potentiai than spectral shift control, are currently being investigated for the PWR. For other than the five-batch, extended burnup fuel management scheme discussed earlier, it appears that only small improvements in fuel resource utilization can be attained with these modifications. The R\&D requirements and licensing effort to commercialize these improvements will probably be comparable to that needed to develop the SSCR. It seems logical therefore to take the step required to pursue spectral shift control as long as the resource savings of this concept are in the range of interest for LWR improvements. A larger benefit can be obtained in a shorter time than by trying to combine a number of the marginal improvement techniques presently being investigated.

The potential for early commercial introduction of the SSCR is greater than that of other advanced converters at least from the point of view that it does not need a large research and development program; there are of course, other factors to consider in a discussion of commercialization. The engineering R\&D could most likely be completed in two to three years excluding the data required for licensing. The possibility also exists that commercial demonstration of the concept can be accomplished in a relatively short time by backfitting a PWR already under construction with the components and auxiliary systems required for spectral shift control, although the cost of PWR downtime for retrofit is an important factor. This technique, with sufficient government support, could result in a SSCR on-line within six to eight years from the time that commitment to the project was made. 
The prospects of rapio acceptance and deployment of the SSCR are also enhanced by the low financial risk inherent in the concept. Since the SSCR can always be operated in the conventional poison-control mode, there is no risk to station generating capacity if the SSCR is deployed, and the financial risk is limited to the cost of the additional equipment required to realize spectral shift control, which is estimated to be only about $4 \%$ of the total cost of the plant.

One of the greatest unknowns associated with the commercialization of a new reactor technology is the licensing process. It is a complex process which requires detailed designs, numerous test data, and the development of sophisticated analysis techniques. For most alternate concepts, the acceptability cannot be judged beforehand since criteria and standards for the new concept do not exist. Reactor vendors and utilities will therefore be reluctant to commit the resources required to develop such material when there is no assurance that they will be acceptable. For the SSCR, licensing is simplified since these criteria and standards are well developed for the LWR and would be generally applicable to the SSCR because of its close association to the PWR.

The technical potential for backfitting an existing PWR for spectral shift operations is very good. However, backfitting results in equipment arrangements which are less optimum than for an original SSCR. Thus, the cost for structures and civil engineering work will be greater. Also, the $D_{2} \mathrm{O}$ inventory will increase because of the less compact equipment arrangement. Installation of the final piping cross-ties will require some plant shutdown. 
The total plant downtime and the overall cost of backfitting will depend strongly on the extent of equipment replacement (e.g., valve and pump seal replacement). A determination of the extent of replacement requires a cost effectiveness study of the actual plant to be backfit. The cost of replacement must be weighed against the costs of added $D_{2} 0$ leakage and higher releases of tritium, which causes a greater occupational exposure to plant workers. Therefore, the overall cost increase for spectral shift operation over the cost for a conventional PWR plant will be higher when backfitting a PWR than for an originally designed SSCR. Thus, backfitting PWRs for spectral shift operation does not appear to be an economically attractive generic concept. Backfitting, however, might be practical as well as economical to get a SSCR-Prototype reactor on line within a relative short leadtime. 
The major conclusions and recommendations resulting from the SSCR study are discussed briefly in this section. The interested reader is referred to the appropriate sections in this report for a comprehensive discussion of these items.

\subsubsection{CONCLUSIONS}

a. The PWR plant equipment modifications to realize the SSCR concept are restricted largely to ancillary components and subsystems, and can be achieved by use of existing equipment of conventional design. The $\mathrm{D}_{2} \mathrm{O}$ upgrader is the only major plant system which is a unique addition to a PWR power plant; however, upgrader units of similar design are in operation in the Canadian HWR system.

b. Because of its improved neutron ecomony (absence of parasitic absorptions in control poison), the SSCR has lower fuel resource requirements than the LWR. Savings in fissile requirements obtained from the use of spectral shift control range from about 10 to $27 \%$, depending on the fuel cycle involved; similar savings in separative work are realized for U-235 fueled cycles.

c. Capital cost estimates for the SSCR are based on costs of a current design PWR plus those additional costs required for spectral shift control. The additional costs total $\$ 26 \mathrm{M}--$ about $\$ 16 \mathrm{M}$ to modify the 
PWR plant for spectral shift control and about $\$ 10 \mathrm{M}$ to construct the $\mathrm{D}_{2} \mathrm{O}$ upgrader. This cost add-on is equivalent to approximately $4 \%$ higher capital costs or $0.38 \mathrm{mills} / \mathrm{kWh}$.

d. The heavy water initial inventory cost is estimated to be about $\$ 54 \mathrm{M}$. This inventory cost is based on a beginning of cycle $D_{2} 0$ concentration of $60 \mathrm{wt} \%$, a conservative value for nearly all fuel cycles. The actual $D_{2} 0$ concentration depends on the specific fuel cycle, the fuel management scheme, and the exact procedure utilized for coolant dilution.

e. Operation and maintenance costs are judged to be only slightly larger than those of the conventional PWR. The slightly higher 0\&M costs are due almost exclusively to the higher costs of performing maintenance on systems containing higher tritium concentrations. The heavy water makeup cost to account for irrecoverable leakage is less than 0.02 mills/kWh.

f. Although fuel cycle costs for the SSCR, including the costs of heavy water, are generally lower than those of the PWR, the higher capital costs and 0\&M costs result in total power costs which are comparable to those of the conventional PWR. For $\mathrm{UO}_{2}$ fuel cycles, the near-term power costs of the SSCR are slightiy higher than those of the PWR, while the long-term power costs are comparable. The power costs of the $\mathrm{ThO}_{2}$-fueled SSCR are competitive with those of the $\mathrm{UO}_{2}$-fueled SSCR only at high $U_{3} 0_{8}$ prices in excess of $\$ 100 / 1 \mathrm{~b}$. 
g. With the exception of the beginning of cycle moderator temperature coefficient (MTC), the safety-related core physics parameters are comparable to those of a conventional PWR. The beginning of cycle SSCR MTC, because of the presence of $D_{2} \mathrm{O}$ and lack of soluble boron is considerably more negative than that of a PWR, resulting in some return to power during a postulated steam-line-break accident. It is felt that the SSCR return to power after a steam-line-break accident is not a significant licensing issue, however, since the estimated magnitude was based on conservative analyses and also the control rod margin can be increased to prevent this return to power. Furthermore, calculated return-to-power during the steamline-break analys is does not by itself preclude the licensability of a reactor; a number of reactors presently operating exhibit this characteristic. Since the consequences of other postulated occurrences and design transients are similar to those of the PWR, it is judged that the SSCR could be licensed after a detailed design has been developed and the safety analysis has been submitted for review.

h. Tritium production in the SSCR is about 20 times greater than in the PWR, leading to considerably higher iritium concentrations in the coolant. This higher concentration of tritium affects, in particular, the refueling operation, maintenance and repair procedures as well as activity releases to the environment. To minimize the impact of the higher tritium concentration, the refueling operation is modified from that of the PWR by utilizing a coolant exchange procedure which replaces the low $\mathrm{D}_{2} \mathrm{O}$ concentration coolant mixture with borated light water. The refueiting operation is otherwise quite similar to that employed in 
the conventional PWR. The higher tritium concentration also will cause adoption of stricter precautions for maintenance and repair work to limit occupational exposures. With respect to activity releases to the environment, the amount of leakage from the primary to the secondary system in the steam generator determines essentially the activity level. Steam generator leakages up to about $30 \mathrm{lb}$. liquid per day do not appear to result in significant plant siting restrictions for the SSCR relative to a PWR.

i. Coolant leakage from the SSCR must be minimized primarily to reduce the potential radiological hazard associated with tritium releases. The majority of the leakage is recoverable and is eventually upgraded for use in subsequent cycles. The irrecoverable leakage constitutes only about $0.2 \%$ of the $\mathrm{D}_{2} \mathrm{O}$ inventory per year. Economically, coolant leakage is not as serious a problem as it is in the HWR because, on the average, the $D_{2} 0$ concentration of the reactor coolant system is only about $30 \mathrm{wt} \%$ and considerably less when the liquid in all the auxiliary systems is included. In addition, the $\mathrm{D}_{2} \mathrm{O}$ upgrader has been sized to process a large volume of low concentration coolant; the added liquid from recoverable leakage represents only a small fraction of this volume.

j. The technology required to deploy the SSCR is already developed and the manufacturing capacity already exists in the form of the LWR and HWR industries. No technological breakthroughs or component development is required to realize the concept. Only engineering development is needed so that the licensing review process will have a sufficient 
data base from which to assess the unique aspects of spectral shift control operation. These factors offer the potential for an earlier introduction of the SSCR compared to that of other advanced converters. In addition, because of the low risk inherent in the concept (e.g., the SSCR can always be operated in the conventional poison control mode), the prospects of rapid acceptance and widespread deployment are enhanced.

a. The present evaluation of the spectral shift control concept has resulted in the development of a conceptual design for a large SSCR employing current design philosophy. This characterization program has identified a number of areas where further development is necessary in order to provide the information which would be required in the licensing process or which would be required to pursue a detailed plant design. As a follow-on to the present evaluation, it is suggested that a program be initiated for the SSCR aimed at resolving those issues which currently might preclude a decision to pursue the development required to eventually deploy the concept. Specifically, it is suggested that interaction with NRC be conducted to confirm that there are no significant licensing problems and that R\&D programs be identified to resolve any outstanding development items.

b. A necessary requisite for deployment of any new reactor concepts is commercial acceptance. It is important, therefore, that electric utility decision makers be consulted to determine what questions/concerns 
they have regarding the SSCR. From this effort, it may be possible to identify additional areas which should receive further engineering development and which will alleviate these concerns and make the spectral shift concept more acceptable.

c. The present evaluation has shown that 10 to $27 \%$ improvement in resource utilization can be obtained through use of spectral shift control. It is felt that further improvement can probably be made by combining a number of core design changes which singly contribute only a small improvement. Those additional changes which have been identified in other DOE programs to improve the resource utilization of the PWR should be investigated for possible incorporation into the SSCR.

d. A number of specific engineering development tasks have been identified in Section 3.5. High on this list is the experimental verification of the effectiveness of the coolant flushing/exchange operation prior to refueling which removes the majority of the $\mathrm{D}_{2} \mathrm{O}$ and tritium from the rest volume remaining in the reactor vessel after system drain down. This procedure, as well as those other items identified, should be pursued until sufficient data is obtained to fully assess their impact on the commercial attractiveness of the spectral shift control concept. 


\section{REFERENCES FOR SECTION 3}

\section{"Summary"}

1. Combustion Engineering Standard Final Safety Analysis Report (CESSAR), Docket Number STN-50-470.

2. SWESSAR-P1, Pressurized Water Reactor Reference Nuclear Power Plant Safety Analysis Report, Docket Number STN-50-495.

3. "Capital Cost: Pressurized Water Reactor Plant," NUREG-0241, June 1977.

4. D. R. Haffner, et al., "Thorium Assessment Program System Studies," TC-1064, Hanford Engineering Development Laboratory, February 9, 1978.

5. Draft Version - NASAP Provisional Data Base for Second Rolling Report, DOE-FCE, July 21, 1978.

6. M. C. Edlund, "Developments in Spectral Shift Reactors," Proc. Third U.N. Conf. on Peaceful Uses of Atomic Energy, $\underline{6}, 314$ (1964). 